\title{
Energy Use Behaviors in Buildings: Towards an Integrated Conceptual
}

\section{Framework}

\begin{abstract}
To achieve significant energy reductions in buildings, decision-makers can engage occupants in different types of interventions such as information sharing, feedback and social marketing. To improve the effectiveness of these energy saving interventions, this study develops and tests a model which is capable of identifying occupants' energy use characteristics and the influential factors of their energy use behaviors (e.g., turning off lights when not in use). The consumer segmentation approach from social marketing is adopted to divide occupants into different categories using three metrics: motivation, opportunity and ability. As a result, a set of hypotheses and corresponding measures are identified to study the effect of influential factors on occupants' energy use characteristics and intentional energy use behaviors. The occupants are then clustered into five main segments that take into account how the occupants will respond to interventions. In the case study, a survey is designed to test the hypotheses and their validity using descriptive statistical analysis and structural equation modeling. The proposed framework is expected to provide decision-makers with useful information to design effective energy saving interventions to reduce overall energy consumption in buildings.
\end{abstract}

\section{Keywords}

Energy use characteristic; Occupants' behavior; Motivation, opportunity, ability model; Structural equation modeling 


\section{Introduction}

The energy consumption of existing buildings in the United States accounts for 41 percent of the national energy use (US EIA 2014), and more than 80 percent of this energy is consumed during the occupancy phase of the building (UNEP 2010). Several research studies emphasized the significant role that occupants can play to reduce energy use and achieve significant energy savings in buildings (e.g., Klein et al. 2012; Moezzi et al. 2009; Sanchez et al. 2007; Wang et al. 2009). Other studies highlighted the need to carefully analyze occupants' energy use characteristics, and corresponding effect on their energy use behaviors to achieve the anticipated energy reductions (Schweiker and Shukuya 2010; Von Borgstede et al. 2013).

One approach is to incorporate occupancy-focused interventions in the building's energy management program (Azar and Menassa 2014b; Carrico and Riemer 2011). These intervention strategies can be designed to invoke either voluntary or involuntary behavior changes in occupants' energy consumption (see Figure 1). Voluntary behavior changes can include education to teach and create awareness about benefits of a particular behavior (Abrahamse et al. 2005); and persuasion that offers reinforcing incentives/consequences to invite voluntary behavior changes at low economic costs. Prior studies have explored different approaches to enable voluntary behavior changes, such as: information distribution outlets (e.g., posters, videos, brochures) (Agha-Hossein et al. 2014; Hayes and Cone 1977; Marans and Edelstein 2010); feedback (e.g., comparing current energy use with historical use that provides consumers with personalized evaluation and a means to monitor progress) (Timm and Deal 2016; Dolan and Metcalfe 2013; Klein et al. 2012; Van Houwelingen and Van Raaij 1989); peer-comparison (e.g., allowing occupants to acknowledge their energy consumption compared to their peers) (He et al. 2010; Peschiera and Taylor 2012; Peschiera et al. 2010); incentives (e.g., monetary incentives); 
and pledging campaigns to encourage energy conservation behaviors (Alahmad et al. 2012; Boyce and Geller 2001; Handgraaf et al. 2013; Whitsett et al. 2013). On the other hand, involuntary behavior changes can include penalties that consist of negative consequences, which discourage an unfavorable behavior; and technological tools and systems (e.g., installing energyefficient insulation materials) that solve problems without any human involvement (e.g., occupancy and light sensors) (Ruzelli 2010; Wong et al. 2003). In general, interventions at education and persuasion level usually deal with posters, emails, or small amount cash incentives which can be implemented at low cost. Penalties can incur extra administrative cost of regulations and sanctions while technology intervention may require retrofit of existing buildings or installing new equipment. The economic and environmental costs associated with these intervention methods increase across the spectrum from voluntary to involuntary methods.

Most of the studies listed above evaluated the effectiveness of the interventions methods on a selected sample of building occupants, and typically report different success rates. However, the main limitations of these studies are as follows. First, none of these studies investigated what occupancy characteristics lead to the success of these interventions as measured by initial and sustained energy use behaviors over time. This is an important gap since several studies have shown that there is often a "rebound effect" where occupants' energy consumption tends to increase after the intervention is removed (Azevedo 2014; Greening et al. 2000; Peschiera et al. 2010). Second, the existing studies assume that occupants react in the same way to intervention strategies. None of them addresses the different characteristics of occupants that play a key mediation role to effectively achieve the intervention objectives. For example, occupants with extreme energy use behaviors will react differently to interventions as compared to others with moderate energy use patterns. Education might be sufficient to reduce the energy use of the latter 
but might need to be supplemented with interventions from higher levels shown in Figure 1 to affect the extreme energy users (Azar and Menassa 2015). Therefore, decision-makers are challenged with designing and delivering these interventions effectively and efficiently due to high uncertainty in predictions of occupants' energy use characteristics, their corresponding behaviors and the resulting energy savings. This uncertainty has mainly emerged due to the different characteristics of occupants which vary based on several factors including occupants' different individual energy consumption rates (i.e., energy use intensity), and dynamic changes in their energy consumption behaviors overtime (Azar and Menassa 2015; Azar and Menassa 2012; Hong 2014). To overcome these challenges, there is a need to understand which influential factors affect occupants' energy use characteristics and their behaviors in buildings. These influential factors play an important role in determining which type of interventions will be more effective and help guide the implementation process of interventions.

A number of research studies have noticed the importance of various characteristics and behaviors of occupants on building energy consumption and investigated them using qualitative and quantitative approaches (Azar and Menassa 2012; Azar and Menassa 2015; Peschiera et al. 2010; Pieters et al. 1998; Hines et al. 1987; Hong et al. 2015; Hong 2014; Klein et al. 2012; Masoso and Grobler 2010; Poortinga et al. 2004). In these studies, occupants' energy use characteristics are widely described to include occupants' energy use intensity, occupants' attitudes and actions they perform (or do not perform) to influence the level of energy consumption; as well as, occupants' connections in a given social network and how those might affect their attitudes and actions. For example, Azar and Menassa (2015) focus on extreme energy use behaviors, and their impact on the overall energy consumption levels that reflect the dynamic aspects of occupancy. The results show that extreme energy users have an important 
negative impact on moderate peers, which can contribute to revoke the benefits of energy saving interventions. These extreme occupants are characterized by a very narrow energy variability (Var), which represents the occupants with strong energy use habits and are harder to influence than occupants with more flexible energy use behavior. Peschiera et al. (2010) assessed the behavioral impact of building occupants when provided with personal energy use data contextualized with different social frames of reference. This study found that occupants' energy use behaviors can be changed by occupancy-focused interventions such as providing peer network utilization and electricity use information, which resulted in a reduction of up to $17 \%$ in buildings energy consumption. Similarly, Pieters et al. (1998) argued that other households' proenvironmental behaviors have a positive impact on consumers' own behavior and emphasized the need for providing feedback among energy consumers. Hine et al. (1987) synthesized 128 studies on pro-environmental behaviors and identified several influential variables such as attitudes, knowledge of issues, verbal commitment. Hong (2014) showed that occupants who are proactive in saving energy consume up to $50 \%$ less energy compared to occupants who do not care about energy use. Moreover, Klein et al. (2012) highlighted that occupant engagement in building energy reduction strategies is critical and can be achieved through interventions of informed feedback and suggestions. They investigated the impact of occupant preferences and behaviors on building energy use and occupants' comfort level, and achieved $12 \%$ reduction in energy consumption and a 5\% improvement in occupants' comfort of a test bed building.

Despite the significant contributions of these studies to analyzing the impact of various energy use behaviors of occupants on the building's energy consumption, they didn't provide a conceptual framework that can be implemented by decision makers to fundamentally understand: what major influential factors affect occupants' energy use characteristics in a particular 
building, and how the latter influence their energy use behavior. Such an approach can provide decision-makers (e.g., facility managers) with information to better design and deliver effective occupancy-focused interventions tailored to occupants' energy use characteristics. To address this research gap, this study extends the literature on occupants' behavior and focuses on developing an integrated conceptual framework which can be adopted in different types of buildings, locations and weather zones to determine the influential factors of occupants' energy use behavior. The work proposed in this paper addresses several research questions identified by Sovacool (2014). First, it presents a conceptual framework that incorporates human-centered research methods such as survey with quantitative approaches including statistical analysis, and agent based simulation to understand the role of occupants in building energy use. Second, this study adopts an interdisciplinary approach from social science and applies it in the domain of energy to identify the influential factors of energy use behavior. The compatibility of the interdisciplinary method in buildings is demonstrated through a case study. Third, the work presented in this paper draws insights from social psychology to measure occupant's energy use characteristics and behavioral change using three constructs: motivation, opportunity and ability. Finally, this study illustrates what type of information and feedback should be used in the intervention strategies to promote energy saving behaviors based on the results of a given building.

\section{Objective}

This paper presents a framework that is capable of identifying influential factors of occupants' energy use characteristics and their corresponding energy use behaviors in buildings to enhance the effectiveness of energy reduction strategies. Therefore, the four main objectives of this study are to: (1) identify major influential components of occupants' energy use characteristics; (2) 
develop a model that establishes the relationship between identified occupants' energy use characteristics and their energy behaviors; (3) illustrate the capabilities of the developed model through a case study of an existing building; and (4) discuss the potential use of the results in an agent based simulation environment (Azar and Menassa 2014b and 2015) to determine energy reduction potential from peer pressure.

\section{Background}

To achieve and improve energy reductions in building sector, several studies proposed technical solutions to reduce energy demand by different building systems (e.g., lighting) (Abraham and Nguyen 2004; Allen 2004). However, these solutions are characterized by highly uncertain energy reduction benefits (Azar and Menassa 2011; Azar and Menassa 2012; Entrop et al. 2010; Poel et al. 2007); relatively high initial costs (Nemry et al. 2010; Scofield 2009; Yudelson 2010); lack of information about the existing building systems making integration of new technologies a daunting task (Bosch and Pearce 2003; Juan et al. 2010); and low taxes and energy prices (Beheiry et. al 2006; Bernstein and Russo 2009), to name a few. In addition, decision-makers who focus only on technological solutions often ignore the significant impact that occupants have on the energy use in buildings (Azar and Menassa 2012; Mahdavi and Pröglhöf 2009; Tanimoto and Hagishima 2009). Due to high energy saving potential, low or even no initial cost, and applicability to both new and existing buildings, many researchers are focusing on studying and modeling occupants' behaviors, and investigating methods that effectively engage occupants in the energy reduction strategies.

Azar and Menassa (2012) conducted an analysis using energy simulation to study the impact of nine occupancy related actions (e.g., after-hours equipment and light use) on energy use in commercial buildings of different sizes and located in 10 different weather climates across 
the US. The results from individual impacts are found to be as high as 30 percent. The combined effect of some of these actions increases the building's energy demand by over 50 percent. In a subsequent study, Azar and Menassa (2014a) illustrated that the way occupants use energy in the building and the methods that facility managers operate the building highly influence the energy consumption levels. They proposed a framework to collect occupancy-focused data and develop energy analysis approach to investigate human-focused energy conservation opportunities in commercial buildings. A case study highlighted inefficiencies in the operation of the heating, ventilation, and air conditioning system (HVAC) increase energy consumption level by as much as 40\%. Other studies such as Chen et al. (2012); Jain et al. (2013); Moezzi et al. (2009); Sanchez et al. (2007); Webber et al. (2006) support these results, and emphasize that significant energy reductions can only be achieved if building occupants are engaged in the process. These studies have significant contributions to the body of knowledge on analyzing the impact of various energy use behaviors of occupants on building energy consumption. However, none of these studies acknowledged how occupants' energy use behaviors are affected by their energy use characteristics. All occupants in these studies are assumed to react in the same way to the proposed intervention implying that they have the same energy use characteristics resulting in short lived benefits to the interventions implemented (Abrahamse et al. 2005).

In order to measure occupants' energy use characteristics and corresponding behaviors, this study adopts a multidisciplinary method combining social science and marketing to develop a model that allows decision-makers to understand the building occupants' energy use characteristics prior to implementing the intervention. The model is based on the consumer segmentation approach from consumer and social marketing (Wolff et al. 2010; Sudbury and Simock 2009; Bayus and Mehtha 1995). The applications of the model in social science and 
marketing field, and its adoption to energy use characteristic context are discussed in detail in the following sections.

\section{Methodology}

Several studies have proposed behavior models to understand the factors that influence human behavior (Fishbein et al. 2001; Michie et al. 2011; Fogg 2009; Ajzen 2005; Hong et al. 2015). For example, Fishbein et al. (2001) identified strong intention, no environmental constraints, and necessary skills as the prerequisites to generate a behavior. Michie et al. (2011) reviewed existing literatures of behavior change interventions and established a Behavior Change Wheel (BCW) framework to guide the design of interventions. The $\mathrm{BCW}$ aims to strengthen the identified weak components in motivation, opportunity, and capability to enhance the effectiveness of behavior change interventions. In Fogg's behavior model (Fogg 2009), an effective persuasive intervention should possess three driving factors: motivation, ability and trigger in order to elicit a targeted behavior. The behavior is only performed when people have sufficient motivation, required ability and appropriate triggers. Some of these models and principles have been examined and introduced to building domain to design and implement energy conservation strategies (Wilson and Marselle 2016; Petkov et al. 2012; Geelen et al 2013; Bang et al. 2006, Staddon et al. 2016). For example, in order to assess the comprehensiveness of BCW framework in the domain of energy behavior, Wilson and Marselle (2016) mapped BCW framework with four energy-behavior change guidance documents. The result indicates energyrelevant behavioral determinants can be generalized into motivation, opportunity and ability (MOA) categories and the most frequently occurring determinants in the documents are reflective motivation, psychological capability, physical and social opportunities. Other studies like Petkov et al. (2012) and Bang et al. (2006) incorporated the persuasive techniques discussed 
in Fogg's model and developed applications which aim to raise awareness of energy related issues and encourage energy efficient lifestyle.

On the other hand, researchers also applied social psychology approaches for understanding and promoting pro-environmental behaviors (DEFRA 2008; Vlek 2000; Abraham and Michie 2008; ThØgersen 1995; Stephenson et al. 2010; Shove 2010), such as Defra 4Es (enable, encourage, engage, exemplify) framework which aimed at promoting sustainable behaviors in accordance with social marketing principles (DEFRA 2008), the needsopportunities-abilities (NOAs) framework for analyzing the determinants of consumer's environmental behaviors (Vlek 2000), taxonomy of behavior change techniques in published intervention descriptions and manuals (Abraham and Michie 2008). Specifically, ThØgersen (1995) adopted the MOA model to analyze consumer behaviors and suggested opportunity and ability as the facilitating conditions of motivation.

However, the aforementioned models and frameworks only used generic behavioral models developed in the field of psychology. None of them demonstrate how to measure occupants' characteristics in energy use domain and analyze their impact on occupants' behaviors. Therefore, to fill this gap and identify the influential factors of occupants' energy use behavior in a particular building, we propose to use the adapted MOA model which maps all the possible factors with motivation, opportunity and ability defined in the energy use domain. To achieve this, we conduct a thorough survey which measures all the factors that may affect occupant's energy use behavior and then adopt the MOA model which has been widely applied in consumer science to study the influence of motivation, opportunity, and ability (MOA) measures on purchasing behaviors. This research approach draws on the analogy between energy intervention strategies and marketing approaches in consumer science. More specifically, the 
segmentation of consumers based on their MOA measures is adopted for this research. This model has traditionally been used to analyze consumers' attention and comprehension processes to brand information, and other significant factors motivating consumers to purchase certain products on a regular basis (Polonsky et al. 2004; Buurma 2001; Machleit et al. 1990; MacInnis et al. 1991; Moorman 1990; Rothschild 1999; Celsi and Olson 1988).

Several studies emphasized that customers' MOA characteristics play a significant role in their purchasing behaviors. For example, Hastak et al. (2001) highlighted the importance of MOA model to determine the communication effectiveness of ads in consumer research. This study found that consumers with loyalty to a particular product have higher MOA levels that help facilitate adoption of this product. MacInnis et al. (1991) studied MOA model to investigate the influential factors such as the extent of brand information processing from ads. Their model proposed that consumers' MOA levels have major impact on the brand information processing stage during and/or after exposure to advertisements. Additionally, Bigné et al. (2010) implemented MOA model to analyze the major drivers of online airline ticket purchases, and identify the effectiveness of perceived channel benefits for consumers in using the Internet to purchase airline tickets. This study reported that MOA model helps to explain 55 percent of the variations in adopting desired behaviors, and is an effective methodology to predict consumers' ticket purchasing intentions.

In this study, we draw on the analogy between MOA characteristics of customers to process brand information and pick up certain products in marketing, and MOA levels of building occupants to interpret energy reduction intervention strategies and adopt energy saving behaviors (e.g., adjusting the thermostat to lower temperatures when leaving the office in heating season). The psychological definition of MOA characteristics, the MOA model in consumer 
science and its adapted interpretation in energy efficiency are detailed in Table 1 and additionally described in subsequent paragraphs.

\subsection{Introduction to the Motivation, Opportunity and Ability Characteristics}

4.1.1 Motivation $(\boldsymbol{M})$ : The psychological definition of motivation is the brain processes that energize and direct human behavior toward goals (Gruen et al. 2005; Hoyer and MacInnis 1997; Michie et al. 2011). More specifically, in consumer science motivation is defined as a goaldirected arousal to engage consumers in desired behavior to process brand information in the advertisement and perform purchasing behavior (Celsi and Olson 1988; MacInnis et al. 1991; Moorman and Matulich 1993; Rothschild 1999; Steg and Vlek 2009; Zaichkowsky 1985) (See Table 1). Motivation measures perceived personal relevance of people and their level of involvement and interest with a particularly provided piece of information (Richins and Bloch 1986; Steg and Vlek 2009; Zaichkowsky 1985). For example, Parra-Lopez et al. (2012) analyzed key factors in human intentions to use social media to organize holiday travel before and during the holiday itself. This study highlighted that consumer's motivation is based on functional, social and hedonic benefits of social media. Moorman and Matulich (1993) highlighted that motivation independently influences consumers' preventive health behaviors, and moderates the impact of ability and opportunity on adopting desired behaviors through encouraging consumers to put their knowledge, skills, or resources into practice.

In this research, we define motivation as an occupant's readiness, willingness, interest and desire to process energy saving information provided through any of the intervention strategies shown in Figure 1, and subsequently adopt the stipulated energy saving behaviors. Thus, the motivation (M) level of occupants measures their perceived personal relevance and the level of involvements with the information presented in the energy reduction strategies (see 
Table 2). For example, occupants with high motivation level can volunteer to attend workshops or receive emails about energy saving tips. As shown in Table 2, motivation metrics are divided into internal and external stimuli indicating that energy related intervention strategies should focus on improving these metrics. For example, improving awareness of energy use implications and desire to receive additional information and guidelines on how to reduce one's own impact.

4.1.2 Opportunity $(\boldsymbol{O})$ : The psychological definition of opportunity is the external factors that make the behavior possible or prompt it (Gruen et al. 2005; Michie et al. 2011). Similarly, in consumer science it is defined as environment factors (e.g., exposure time to ads) that are not in the control of consumers to enable desired actions (Bigné et al. 2010; Hallahan 2001; MacInnis et al. 1991; Rothschild 1999) (See Table 1). Opportunity level is directly related to the immediate environment of the people and how that affects the availability, accessibility, and time allocated for comprehension of the brand information (Rothschild 1999; Maclnnis et al. 1991; Celsi and Olson 1988). Other studies described opportunity level as the extent to which circumstances evidenced during advertisement exposure are favorable for brand processing (Govindaraju et al. 2013; MacInnis et al. 1991; Rothschild 1999). For example, Govindaraju et al. (2013) studied key drivers for physicians to adopt electronic medical records (EMR), and extended "opportunity" context to physicians" "access to EMR system" and "access to information" which refer to the physicians' opportunity to get in contact with any information media and other sources.

In this research, opportunity $(\mathrm{O})$, refers to the surrounding environmental factors influencing occupants' attention and comprehension processes in adopting energy saving behaviors. As shown in Table 2, when occupants have easily accessible building controls, opportunity metrics can be improved during an intervention by focusing on the amount, format, 
modality and rate of exposure to the information. Thus, opportunity measures how favorable conditions and limited time of exposure affect the occupant's attention to information being presented in the energy intervention strategies.

4.1.3 Ability (A): The psychological definition of ability is the necessary capabilities (psychological and physical) to make an outcome happen (Blumberg and Pringle 1982; Gruen et al. 2005; Michie et al. 2011). In consumer science, ability definition is modified to focus more on psychological aspects and it is defined as consumers' self-perception knowledge capacity of the brand information, and how they interpret this information to create new knowledge structures (Bigné et al. 2010; Celsi and Olson 1988; MacInnis et al. 1991; Parra-Lopez et al. 2012) (See Table 1). Ability level is largely dependent on the consumer's prior knowledge about brand information typically acquired through experience; as well as, the consumer's skills in interpreting brand information in an advertisement (Celsi and Olson 1988; Rothschild 1999). For example, Bigné et al. (2010) defined ability level as individuals' perception of their capacity to search for information about flights on the Internet and to carry out online purchases of airline tickets. Results show that customers' Internet ability positively influences their intentions to purchase online airline tickets.

In this research, ability (A) level of occupants measures a given occupant's proficiencies in interpreting energy use knowledge. This ability (A) (see Table 2) is largely dependent on the occupant's prior knowledge about energy use, its impact and consequences, as well as knowledge about possible conservation strategies. The type and quality of this pre-existing knowledge will in turn determine if energy use information can be cognitively and immediately retrieved in a given situation (e.g., occupants turn lights off before leaving their offices). 


\subsection{Framework for Measuring MOA Levels of Building Occupants}

Previous studies (e.g., medical field, ticket purchasing website) found out that motivation is directly associated with most behaviors (Moorman 1990; Bigné et al. 2010). However, opportunity and ability affect behaviors only when motivation is present, which means these two characteristics moderate the impact of motivation on behaviors. Therefore, in this research we propose motivation as a precondition of successful implementation of energy saving behaviors with opportunity and ability as moderating factors, and design the framework described in following section accordingly. The proposed framework in this study is developed by stating a set of research hypotheses and their relevant measures to investigate occupants' energy use characteristics through assessing their MOA level on adopting energy saving behaviors. These hypotheses are designed based on the extended context of MOA levels of occupants in energy use characteristics, and incorporated with a set of measures that is identified based on a comprehensive literature review, as shown in Figure 2. These measures are utilized to demonstrate the link among each motivation, opportunity, and ability levels of occupants, their related research hypotheses, and their intended energy use behaviors.

4.2.1 Identifying Measures for Occupants' Motivation Characteristic: As mentioned earlier, motivation level (M) refers to a particular occupant's perceived personal relevance in terms of needs, goals and values, and the level of involvement with the information (e.g., external stimuli) presented in the energy intervention strategy. Therefore, occupants' concern and desire of energy conservation are investigated as the measure of their motivation. Motivation level independently affects occupants' energy use behaviors, how often they look for ways to conserve energy at 
their offices, and which factors are important for them to conserve energy, as shown in Figure 2. Accordingly, the related hypothesis is stated as follows:

H1: Occupants with higher energy conservation motivation levels will perform more energy conservation behaviors than occupants with lower energy conservation motivation levels.

4.2.2 Identifying Measures for Occupants' Opportunity Characteristic: In this research, occupants' opportunity $(\mathrm{O})$ level is directly related to their immediate environment and how that affects the availability and accessibility for comprehension of the energy use knowledge. Adopting Moorman and Matulich (1993) approach, we assume that occupants' opportunity level moderates the effect of motivation on energy saving behaviors. For example, highly motivated occupants are not able to present energy saving behaviors in their offices such as adjusting thermostat control when leaving the office, if they do not have any control on their room's thermostat. Studies have shown that people have more tendency to make permanent changes in their energy use behaviors when they have available resources and if the new behaviors are easy and convenient to perform (McMakin et al. 2002). Therefore, opportunity level of occupants in this study is measured by investigating (see Figure 2): (i) availability of energy conservation control systems (e.g., if the occupant has any individual control on the indoor climate control system); (ii) office environment satisfaction level (e.g., overall quality of artificial lighting in the office); and (iii) exposure to information and peer-pressure about environmental concerns through interventions (e.g., having energy conservation information available for occupants on bulletin boards and often discuss environmental conservation strategies with colleagues). Accordingly, the corresponding hypotheses are stated as follows: 
H2: When energy conservation motivation is high, occupants with higher control over their indoor environment will perform more energy conservation behaviors.

H3: When energy conservation motivation is high, occupants who are satisfied with their indoor environment will perform more energy conservation behaviors.

H4: When energy conservation motivation is high, occupants with more exposure to information about the environmental impacts of their energy use behaviors will perform more energy conservation behaviors.

4.2.3 Identifying Measures for Occupants' Ability Characteristic: In this research, ability level measures each occupant's proficiency in interpreting energy use knowledge. This ability is largely dependent on two major factors: occupant's perception on their energy consumption level, and occupants' prior knowledge about energy use facts. A set of studies has shown that people need to have sufficient ability (e.g., self-efficacy) before they can actively care enough to take environmentally responsible actions that benefit others (Eccles et al. 2005; Geller 1981; Southwell and Torres 2006; Wilson and Dowlatabadi 2007). These studies highlighted that occupants' ability (A) level also moderates the effect of motivation (M) on adopting certain behaviors. Abrahamse and Steg (2009) concluded that occupants with higher perceived energy conservation knowledge (e.g., "I know how to reduce cooling load in summer") and knowledge on energy consumption facts (e.g., what a kWh unit means) are more likely to save energy than occupants with lower energy use knowledge. On the other hand, previous studies show that higher ability levels may reduce consumers' acquisition of information if they feel less need for more information (Moorman 1990). Therefore, it is also important to ensure that knowledgeable occupants are also highly motivated to maintain their energy conservation behaviors. Based on Abrahamse and Steg (2009), occupant's knowledge-based ability level is measured by (i) 
perceived energy conservation knowledge (we assume their self-claimed knowledge is correct), and (ii) level of knowledge on energy consumption facts, as shown in Figure 2. Accordingly, related hypotheses are stated as follows:

H5: When energy conservation motivation is high, occupants with higher perceived energy conservation knowledge will perform more energy conservation behaviors.

H6: When energy conservation motivation is high, occupants with better knowledge of energy consumption facts will perform more energy conservation behaviors.

\subsection{Framework Implementation}

The proposed framework is implemented in four phases (as shown in Figure 3): (1) survey phase that involved designing an online survey to test the stated hypotheses; (2) reliability analysis phase that analyzes results from survey for integrating the measures of stated hypotheses in the same construct; (3) structural equation modeling (SEM) phase that investigates the relations among motivation, opportunity, ability, and intentional energy use behaviors of occupants; and (4) data output phase that proposes energy use reduction strategies for the building occupants given their energy use characteristics and predicts the expected energy savings. The following paragraphs provide detailed explanation of each phase of the research.

4.3.1 Survey Design Phase: An online survey is developed to collect data to test the stated hypotheses, and identify occupants' motivation, opportunity and ability level and their corresponding behaviors. The survey is designed to be flexible for use both in residential and commercial building settings. To test and validate Hypothesis 1 (i.e., H1), two measures were identified as: (1) occupants' concern level on their personal energy consumption (e.g., how often are you concerned about your personal energy consumption at your office?), and (2) factors 
deciding whether to conserve energy (e.g., how important are the following factors to you in deciding whether to conserve energy?).

Hypothesis 2 (i.e., H2), Hypothesis 3 (i.e., H3), and Hypothesis 4 (i.e., H3) are tested through measures presented in Figure 2. H2 measures if occupants' energy use control levels have an impact on their energy conservation behaviors when they have motivation to conserve energy. In the survey, measures of $\mathrm{H} 2$ are identified as the availability of lighting control, availability of thermostat control, and availability of office equipment (e.g., printer) plug load control for the occupants. H3 predicts that office (or residence) environment satisfaction levels have an effect on occupants' energy conservation behaviors in the presence of energy conservation motivation. The measures of $\mathrm{H} 3$ are designed as occupants' satisfaction with lighting quality level (e.g., how would you describe the quality of artificial lighting in your typical work area?), thermal comfort level, and indoor air quality level in their offices. H4 studies whether occupants exposed to environmental conservation information changes their energy conservation behaviors, when they are also motivated to conserve energy. This hypothesis is tested using the measures of occupants' exposure level to environmental concern through company's (or landlord) actions (e.g., my company provides all employers with strategies to help us conserve energy), and peer-pressure among co-workers (or neighbors) (e.g., my close friends in the company always use strategies to conserve energy).

Finally, to test and validate ability level of occupants, the last two hypotheses, Hypothesis 5 (i.e., H5), and Hypothesis 6 (i.e., H6), are tested through measures presented in Figure 2. H5 studies if the occupants' perceived energy conservation knowledge level would affect their energy conservation behaviors when they are motivated to conserve energy. H5 is tested using the measure of occupants' self-assessed knowledge level (e.g., I know methods to reduce heating 
load in my office). On the other hand, H6 determines if occupants' knowledge level of energy consumption facts would have impact on energy conservation behaviors when energy motivation is high. The measures for $\mathrm{H6}$ are designed as six test questions asking occupants about their knowledge on energy consumption facts (e.g., which lighting choice saves the most energy assuming the same delivered amount of light?).

4.3.2 Reliability Analysis Phase: Reliability analysis needs to be conducted where the survey data is analyzed to check the internal consistency of multiple measures. Through reliability analysis, highly correlated questions are combined as one composite question to reduce multicollinearity and make the multi-item integration intensity scale to be unidimensional (Ray et al. 2005; Rosenzweig et al. 2003). In this research and as illustrated in the Case Study section, the results for the reliability analysis are assessed based on the recommended threshold of: Cronbach $\alpha$ with a value of $\alpha=0.70$ (Nunnally 1978), and inter-item correlation with a value of 0.30 (Hair 2010). Questions with Cronbach $\alpha$ greater than 0.70 and inter-item correlation greater than 0.30 are combined into a single construct. For example, plug load control can combine four correlated equipment questions (i.e., printer, fax, fridge and microwave oven) into one measure of opportunity (O).

4.3.3 Structural Equation Modeling Phase: Structural equation modeling (SEM) phase is implemented to test and validate the stated hypotheses. SEM is a confirmatory multivariate analysis methodology for hypotheses testing, which has a capability of constructing variables that may explain major part of the unobserved heterogeneity in the model (Bollen and Long 1993). In social science and marketing field, several research studies implemented SEM models to investigate the influential factors on consumers' characteristics and their behaviors (AlMaghrabi et al. 2011; Bigné et al. 2010; Bruner and Kumar 2005; Childers et al. 2002; 
Govindaraju et al. 2013; Van der Heijden et al. 2003). Childers et al. (2002) studied the dominant factors in customers' online retail shopping behavior using SEM. Results indicated that hedonic aspects of the new media play at least an equal role as instrumental aspects to predict online attitudes. Van der Heijden et al. (2003) used the same method to explore factors that influence consumer's purchasing behavior at an electronic commerce website and found out a strong positive relation exists between attitude towards online purchasing and corresponding purchasing intention. This research also suggested that perceived risk and ease of use are antecedents of attitude towards online purchasing.

In this research, SEM methodology is implemented using Stata (2015) where exogenous variables (e.g., quality of artificial lighting in working zone) are computed as factors affecting endogenous outcome (i.e., intended energy use behavior of occupants like turning off the monitor when not in use). A detailed description of the setup of SEM model and how the resulting data are interpreted is explained in the Case Study Section.

4.3.4 Results and Energy Implication Phase: This phase helps decision-makers analyze the identified influential factors on occupants' energy use characteristics, and their behaviors to design effective occupancy-focused intervention strategies. The proposed motivation/opportunity/ability (MOA) model can monitor the effectiveness of the intervention strategies (e.g., effect of peer pressure, resulted energy savings). By comparing occupants' MOA level at different stages throughout the intervention, decision-makers can identify the weak component of MOA in occupants' characteristics and modify their interventions accordingly over time.

To achieve this objective, a k-means clustering analysis is conducted using Matlab to organize occupants in groups with similar MOA characteristics (MacQueen 1967). According to 
the individual MOA level and the MOA distribution within the building clusters, an occupant can be categorized as prone, mildly unable, unable, mildly resistant or resistant to change the energy use behavior. In this study, the results of the MOA model are integrated with the AgentBased Model (ABM) which studies how occupants interact and respond to energy saving interventions to provide an initial prediction of the effectiveness of the chosen intervention. Details about this model and its functionalities can be found in Azar and Menassa (2014b) and Azar and Menassa (2015).

At the agent initialization phase, each agent (or occupant in our context) is associated with two variables: (1) energy intensity (EI) in $\mathrm{kWh} /$ person, which defines the energy consumption level of an agent, and (2) energy variability (Var), which refers to an agent's openness to adopt new energy use characteristics (Azar and Menassa 2015). Data about the occupants' energy intensity is obtained from building energy use data or from historical databases such as the Commercial Building Energy Consumption Survey (CBECS) published by the Energy Information Administration (EIA 2003). The average energy consumption can be treated as the median EI, and occupants who are well performed in energy use tend to have a low EI and vice-versa. Occupants' MOA characteristics (prone, mildly unable, unable, mildly resistant, resistant) can be mapped with the Var parameter, where occupants who are prone to change behaviors tend to have a high Var (i.e., flexible habits) while those with resistant MOA characteristics tend to have a very low Var (i.e., rigid habits). As a result, the agents which are initialized by MOA level can reflect the real occupancy characteristics in the building. The implications of this approach and its ability to predict energy savings given an intervention strategy are illustrated in the Case Study section.

\section{Case Study}


A total of 177 occupants in a 32-story building in Chicago, IL, responded to the survey which was distributed online. The case study building is a multifunctional building of a university which contains classrooms, student dorms, administrative offices, etc. Participants are mainly from offices located on floors 6 to 10 representing administrative staff in a typical office environment. In total, 205 people routinely occupy the surveyed floors (survey response rate is $86 \%$ ). The case study building is equipped with a building automation system (BAS) with a centralized monitoring and control of building environment to maintain the operational performance of the facility, and comfort of the building occupants. This BAS system provides occupants with different levels of occupancy control over the building environment. For example, some occupants especially in single occupancy rooms are able to control the thermostat settings, shading and lighting. On the other hand, occupants in multi-occupancy rooms do not have much control, which may lead to various energy use behaviors among the occupants in the same building.

The demographic information of the respondents are as follows: (1) $65 \%$ are female and $35 \%$ are male; (2) $9 \%$ are between the age of $20-30$ years, $43 \%$ are between the age of $30-49$, and $48 \%$ are older than 49 years; and (3) $8 \%$ have high school degree; $26 \%$ have college level degree; 66\% have a graduate level degree of Master's (e.g., MA, MS, MENG) and/or PhD (e.g., $\mathrm{PhD}, \mathrm{EdC})$. The survey results were then reviewed for completeness resulting in a total of 130 (i.e., 73 percent of the total surveys filled out) fully completed surveys which were subsequently used for the reliability and SEM analysis.

Through reliability analysis, some highly correlated measures in the survey are combined into simple constructs (see Table 3) to determine occupants' MOA level. As shown in Table 3, the Cronbach coefficient $\alpha$ for some listed measures is greater than the recommended cut-off 
value of 0.7 and thus can be combined into a single construct. Other measures with low Cronbach $\alpha$ (e.g., availability of the lighting control) can't be combined together and are used directly in the SEM model. Some measures are reported as "not applicable" by all the respondents (e.g., availability of the space heater) and thus are removed from the SEM model.

The distribution of occupants' MOA level and behaviors are shown in Figure 4 and Figure 5 respectively. Figure 4 shows that around $30 \%$ of the occupants in this office building (36 out of 130) are highly motivated, and around 14\% of them (18 out of 130) possess high ability level. However, the opportunity level is relatively low (77 out of 130 possess low or medium-low opportunity level) compared to the other two characteristics, with only 5 occupants having a very high opportunity level. This might be a direct result of the limited ability placed on the occupants by the existing BAS, which reduces the occupants' potential to contribute to energy saving.

Figure 5 shows the number of occupants who perform well for different energy use behaviors considered in the study. Occupants report several poor energy use behaviors, such as Behavior 4 (i.e., B4: turn off the monitor when not in use), Behavior 5 (i.e., B5: turn off the computer when not in use), Behavior 6 (i.e., B6: adjust shades to reduce glare), Behavior 7 (i.e., B7: adjust shades to increase day lighting), Behavior 8 (i.e., B8: adjust shades to reduce heat from the sun), and Behavior 9 (i.e., B9: turn off the light when there is enough daylight). For B4, B5 and B9, occupants fail to show better energy use behaviors even though most of them have control to the equipment (lighting and computer), that is they have a high opportunity to do these actions. The low action rate of B6, B7 and B8 is because many occupants (52 out of 130) reported that they have no control to the shading system, which indicates a strong correlation between opportunity and behavior response. 
In SEM, models are illustrated in a path diagram. The boxes represent observed variables (or indicators) that are observed in the data. These variables are actually what are measured from particular questions on the survey (e.g., lighting quality). Circles are unobserved latent variables that are measured by a number of observed variables (e.g., occupant's exposure to information is measured by company's action and peer pressure). Single head arrows, called paths, connect variables in the path diagram. When a path points from one variable to another, it means that the first variable affects the second (e.g., the arrow between motivation and behaviors represents that motivation is a predictor of behaviors). According to the measures for MOA level discussed in Figure 2, an SEM model is constructed to test the proposed hypotheses (see Figure 6). For example, to test $\mathrm{H} 2$ "occupants with higher control over their indoor environment will perform more energy conservation behaviors when motivation is high". Latent variable "Control level" is indicated by three observed variables: lighting, thermostat, and plug load control. Then "Control level", Motivation and Behaviors are connected using paths to represent their proposed relationship. The best four occupants' behaviors shown in Figure 5 (i.e., Behavior 1 - 4) are selected to represent the occupants' intentional energy use behaviors. However, the abovementioned structure of SEM model depends on the data collected from the case study building. Several structures are evaluated in Stata to accept the model (See Figure. 6) which best fits the data. The SEM model might look different in other buildings (e.g., M, O, and A are the distinct precursors of energy use behaviors and are parallel to each other) but the framework presented in this paper can be adopted to achieve the best fit model. In this study, model fit statistics obtained from survey results indicate that $R^{2}=0.174$. However, because people are fairly unpredictable, it is difficult to only use $\mathrm{R}^{2}$ to evaluate the model fit to the data (Minitab 2014). Therefore, the widely adopted root mean squared error of approximation (RMSEA) is also used to measure the 
misfit/fit of the SEM. The RMSEA of the developed model is 0.05 , which is equal to the ideal standard of "less than or equal to 0.05" (MacCallum et al. 1996, Acock 2013). Also, the Normalized Chi-Squared value of the results is $X^{2} / d f=0.80$, which is a reasonably good indicator of model fit (Kline and Santor 1999). Therefore, the model shown in Figure 6 was accepted as the best fit model for this particular building.

The results from SEM analysis are presented in Table 4. As shown in Table 4, $\beta$ is the coefficient of observed variable and latent variable. For each change of one unit in observed variable, the latent variable will change $\beta$ units while holding all other observed variables constant (Stata 2013). By examining the $\mathrm{p}$ value, statistically significant coefficient is highlighted with a label (“*” for $\mathrm{p}<0.1$, “**” for $\mathrm{p}<0.05$ ). The subsequent subsections explain the implication of these results for the case study building.

\subsection{Test of the Hypothesized Relationships}

Hypothesis 1 predicts that energy conservation motivation will positively affect all of the intended energy conservation behaviors. The results show that occupants' motivation level has positive effect on some energy use behaviors like turning off the office lights $(\beta=0.34, p<$ $0.05)$, and computer monitors when not in use $(\beta=0.24, p<0.05)$. However, there is no significant correlation (abbreviated as " $n s$ ") between occupants' motivation to conserve energy and occupants' energy conservation behaviors when the office is: (i) too chilly/cold (e.g., wearing a thick clothes, using space heater) $(\beta=-0.02, n s)$, and (ii) too warm/hot (e.g., wearing a thin layer of clothing, using an electric fan $)(\beta=-0.03, n s)$. These findings indicate a mixed support for Hypothesis 1.

Hypothesis 2 looks at whether energy use control levels affect energy conservation behaviors in the presence of energy conservation motivation. The results indicate that having 
thermostat control to adjust the indoor climate conditions is negatively and significantly correlated with occupants' motivation $(\beta=-0.32, p<0.1)$. This result indicates that for this case study building, even if some occupants have no control on thermostat, they still have high motivations to conserve energy. Moreover, there is no significant correlation between occupants control on office equipment's plug load (e.g., printer, microwave oven) $(\beta=0.13, n s)$ and on lighting $(\beta=-0.11, n s)$, and occupants' motivation to conserve energy. These results do not support Hypothesis 2.

Hypothesis 3 determines if higher office environment satisfaction levels would affect occupants' energy conservation behaviors in the presence of energy conservation motivation. For example, occupants with higher thermal comfort level tend to perform more energy saving behaviors than occupants with lower thermal comfort level when their motivation is high. The results indicate that there is no significant correlation between occupants' motivation and their lighting comfort level $(\beta=-0.06, n s)$, and indoor air quality level $(\beta=-0.09, n s)$. However, occupants' thermal comfort is positively and significantly correlated with occupants' motivation to conserve energy $(\beta=0.16, p<0.1)$. This finding can be evaluated as providing higher thermal comfort level in the office will increase the motivation level of occupants to conserve energy. Accordingly, these results present a mixed support for Hypothesis 3.

Hypothesis 4 studies if higher exposure to ambient conservation information will positively affect energy conservation behaviors in the presence of energy conservation motivation. This hypothesis is tested under two conditions, occupants' exposure to information through (i) company's energy saving actions, and (ii) peer-pressure from co-workers. The results show that peer-pressure is positively and significantly correlated with occupants' motivation to conserve energy $(\beta=0.19, p<0.1)$. If an occupant observes his/her co-workers always use 
strategies to conserve energy, he/she will also be highly motivated to conserve energy. Direct exposure to energy conservation-related information, however, does not have any effect on occupants' energy conservation motivation $(\beta=-0.01, n s)$. These results indicate a mixed support for Hypothesis 4.

Hypothesis 5 determines if the perceived energy conservation knowledge has a positive impact on energy conservation behaviors in the presence of energy conservation motivation. The results indicate that there is a positive and significant correlation between occupants perceived knowledge on energy conservation and occupants' motivation to conserve energy $(\beta=0.23, p<$ 0.05). This result indicates that higher perceived energy conservation knowledge results to higher motivation of occupants. These findings indicate support for Hypothesis 5.

Hypothesis 6 determines if higher knowledge level of energy consumption facts would lead to more energy saving behaviors, such that more knowledgeable occupants would perform more energy conservation behaviors than less knowledgeable occupants when energy conservation motivation is high. The results indicate that there is no significant correlation between occupants' knowledge level on energy consumption facts and their motivation $(\beta=$ 0.16, ns). Therefore, these results do not support Hypothesis 6 .

The results from SEM analysis which used to test six hypotheses stated in this study present several strategies to improve the motivation, opportunity and ability level of occupants in the chosen building, and accordingly their energy use behaviors for adopting energy reduction strategies.

\subsection{Discussion of SEM Analysis Results}

Based on the results obtained from the previous section, higher occupants' motivation level (e.g., looking for ways to conserve energy in the office) can lead to some energy saving behaviors. 
Therefore, occupancy interventions aiming at better occupants' behaviors can focus on improving occupants' motivation level. Moreover, we identified two factors of opportunity characteristic and one factor of ability characteristic which demonstrate strong correlations with occupants' motivation from the list of surveyed factors as shown in Table 3. These three factors are the major influential factors of occupants' energy saving behavior in this particular building. Therefore, to promote energy saving behaviors, occupancy interventions can be designed to: (1) provide occupants with thermal comfort conditions; (2) increase the peer-pressure among the workers, and (3) enhance occupants' self-assessed knowledge on energy conservation to promote their motivation level. For example, facility managers of the analyzed case study building can install thermostat in each office room to improve the indoor thermal comfort, and also send regular emails (e.g., weekly) to occupants presenting their personal energy usage and a comparison of the energy consumption among colleagues as well as some tips of daily energy saving behaviors.

These findings from the case study analysis also support the research studies conducted by (Agha-Hossein et al. 2014; Dolan and Metcalfe 2013; Hayes and Cone 1977; He et al. 2010; Klein et al. 2012; Marans and Edelstein 2010; Peschiera and Taylor 2012; Peschiera et al. 2010). Agha-Hossein et al. (2014), Dolan and Metcalfe (2013), and Hayes and Cone (1977) stated that information distribution of energy consumption facts and reduction guidelines do not appear to effectively influence occupants. Moreover, He et al. (2010); Marans and Edelstein (2010) demonstrated that feedback and peer-comparison are the most effective education methods to influence occupants' energy conservation behaviors. Klein et al. (2012) highlighted that occupant engagement in building energy reduction strategies is critical and can be achieved through informed feedback and suggestions. Peschiera and Taylor (2012) and Peschiera et al. 
(2010) presented that energy use feedback interventions which monitor and report building energy use of peers are very effective in promoting energy reduction strategies. Additionally, the finding of thermal comfort as an influential factor of energy saving behaviors also conforms to Maslow's hierarchy of needs (Maslow 1987). Occupants are willing to take energy saving actions and make contributions to the environment (self-actualization) only when their

fundamental needs (e.g., physiological needs of thermal comfort) have been satisfied.

However, it should be noted that these results highly depend on the data collected from the case study building. The major influential factors identified in this study may not remain the same for other buildings. For the non-influential factors, further investigations in the workplace can be conducted to identify the reason why these factors don't show a strong impact on energy saving behaviors. It might seem counterintuitive that people with control of lighting and office plug loads fail to perform more energy saving behaviors. However, there can be several reasons leading to such situations. For example, some office equipment are public appliances (e.g., printer, microwave oven) which are not managed by a single person. It is also likely that occupants may not turn off the light in a multi-occupancy room even if there is enough daylight because the switch is next to an overbearing colleague who can be annoyed when bothered. Moreover, company's eco-promotion may fail if the posters are not noticeable to the employees, or the proposal is difficult to perform.

\subsection{Energy Savings Implications}

This section explains how the results obtained from the MOA and SEM analyses can be used to predict potential energy savings from chosen intervention strategies. First, k-means clustering analysis is conducted to group the occupants in five categories (as shown in Figure 7) based on each occupant's MOA level measured from on a scale of 0 to 100 . The centroid of each cluster is 
calculated (see Table 5) and then mapped with occupant's MOA characteristics. For example, occupants in prone category have the highest motivation (80) and relatively high opportunity (51) and ability level (61) while occupants in resistant category have the lowest motivation (20), opportunity (30) and ability level (21). More details about clustering occupants can be found in Aslihan et al. 2016. This supports the findings as discussed in the SEM analysis, a higher opportunity and ability level will promote an occupant's motivation to conserve energy. For this case study building, the number of occupants in each category (from prone to resistant) is 29, 30, 29,37 and 5 correspondingly.

As shown in Figure 6, peer pressure is one of methods that is shown to improve opportunity level of the occupants and thus having a positive influence on their motivation level. Therefore, peer pressure functionality in the Agent-Based Model (Azar and Menassa 2014b and Azar and Menassa 2015) is selected to study the potential impact of this intervention on reducing the occupant's energy consumption in the building. The occupants are assumed to form a single small world network, and their energy intensity (EI) is initialized using log normal distribution $(\mu=1.626, \sigma=0.875, \min =0.272)$, emulating the energy consumption of a typical US office buildings based on CBECS data (2003). However, the energy variability (Var) and corresponding number of people are established based on the MOA characteristics from this study. Occupants in prone category have the largest Var, followed by mildly unable category, unable category, etc. During the simulation, occupant's EI and Var change due to presence of peer pressure. When the model reaches convergence, the result shows that 95 out of 130 occupants have reduced their EI. The average EI decreases from 6.93 to 4.19 $\mathrm{kWh} / \mathrm{m} 2 /$ person/year. Figure 8 shows the original number of occupants in each of the five categories and the corresponding number of occupants in each category who reduced their 
energy consumption. These results support the conclusions from the SEM analysis that peer pressure in this case can enhance the opportunity level of the occupants, which directly improves their motivation level and thus their energy use behavior. However, if the building has a large number of people in each cluster (or in a multi-tenanted building), different interventions can be considered for each cluster. The choice of multi-interventions is beyond the scope of this paper and is part of our future research efforts to map building occupancy clusters obtained based on MOA to different interventions.

\section{Limitations}

This research has a number of limitations. First, as pointed out by several studies (Ajzen 2005; Fogg 2009; Michie et al. 2011), the behavioral determinant ability includes both psychological and physical capability or effort to engage human in a targeted behavior. In our MOA model, ability is mainly a knowledge-based measure which affects occupant's interpretation, comprehension, and reasoning about energy use information. Physical capability is excluded from the measurements (E.g., light switches are set too high for a wheelchair user to reach it). However, through the evaluation of behavior change wheel (BCW) framework in the domain of energy behavior, Wilson and Marselle (2016) found physical capability to be the least frequently occurring determinant in behavior change guidance documents. They argue that physical capability might be more common in health field compared to energy behavior domain, which requires further investigation. Second, when evaluating ability level, occupants' perceived knowledge about possible conservation strategies are assumed correct, which might not always be true. Occupants' wrong assumption about energy conservation actions might turn out to be counterproductive. Third, the proposed framework mainly focuses on individual's MOA level to determine energy use characteristics. However, other social factors (e.g., education, religion, 
economic status, lifestyle) may also collectively affect an occupant's energy behavior, which requires research studies to use more generic metrics in the future. Fourth, motivation level is treated as an overall measure of occupant's concern and desire of energy conservation. However, in reality people may have a mixed level of motivation for different behaviors (e.g., people may be more motivated to turn off the light than to adjust the thermostat). Fifth, the proposed framework is only tested in commercial buildings. In residential properties, utility bill can become a key factor of energy use. Future studies will take household energy bill into consideration when investigating the influential factors in residential buildings.

\section{Conclusion and Policy Implications}

This study developed a framework which is capable of identifying the influential factors on building occupants' energy use characteristics and their relevant behaviors to adopt energy reduction strategies. To achieve this, the study proposed an approach from social sciences which adopts an analogy of motivation/opportunity/ability (MOA) model and marketing field. Based on this analogy, the MOA definitions are adapted to context of energy use in buildings, and a set of research hypotheses and a corresponding survey are developed to evaluate the MOA influential factors. The developed model is implemented using structural equation modeling (SEM), a widely used approach in behavioral sciences, to investigate the direct impact of occupants' energy use motivation level, and moderating effect of their opportunity and ability levels on energy use behaviors. Agent based modeling (ABM) is then used to estimate the potential impact of the chosen intervention on energy reduction. The results obtained from the case study building demonstrate the model's capability for achieving the objectives described in this paper.

It is worth noting that the major contribution of this study is the flexible evaluation framework, which may vary from case to case due to different building types, weather zones, 
occupancy states (multi-tenanted vs single company) to name a few. This framework can be adopted and modified according to the actual situation of a given building. Decision-makers can first analyze the influential factors and MOA levels relevant to their building, and then use the resulting information to design occupancy-focused energy reduction intervention strategies tailored to occupants' characteristics in their building. For example, if a building has a high percentage of occupants who are identified as "prone" to change energy use behaviors after distributing the survey and analyzing the data following the approach proposed in this study, then the chosen intervention strategies can focus on knowledge-based approaches such as education (see Figure 9). For buildings which show diverse occupants' characteristics, multilevel interventions can be adopted to account for different groups of occupants. Although the implementation and testing of an intervention design in this manner are outside the scope of this paper, the results from the agent based simulation analysis illustrate that energy savings are possible when the right type of intervention is designed. This approach of designing and implementing interventions based on occupancy characteristics is bound to improve the effectiveness of occupancy-focused interventions and providing sustainable energy reductions in buildings. In particular, policy makers can implement this methodology to obtain an understanding of the population perspective in city blocks, urban environments or residential neighborhoods. They can then use the results to determine which of the $\mathrm{M}, \mathrm{O}$ or A needs to be supplemented or addressed by the intervention method or policy to achieve large scale and effective energy reductions.

Future research by the authors will focus on collecting energy use data from building automation systems to correlate actual levels of energy use to intentional occupancy behaviors. 
This will allow the research team to subsequently be able to design and test intervention strategies under different scenarios.

\section{REFERENCES}

Abraham, M. A. and Nguyen, N. (2003). Green engineering: Defining the principles. Environmental Progress, 22(4), 233-236.

Abraham, Charles, and Susan Michie. "A taxonomy of behavior change techniques used in interventions." Health psychology 27.3 (2008): 379.

Abrahamse, W., Steg, L., Vlek, C., Rothengatter, T. (2005). A review of intervention studies aimed at household energy conservation. Journal of environmental psychology, 25, 273291.

Abrahamse, W., and Steg, L. (2009). How do socio-demographic and psychological factors relate to households' direct and indirect energy use and savings? Journal of economic psychology, 30(5), 711-720.

Acock, A. C. (2013). Discovering structural equation modeling using Stata. Stata Press books.

Agha-Hossein, M., Tetlow, R., Hadi, M., El-Jouzi, S., Elmualim, A., Ellis, J., and Williams, M. (2014). Providing persuasive feedback through interactive posters to motivate energysaving behaviours. Intelligent Buildings International(ahead-of-print), 1-20.

Ajzen, Icek. Attitudes, personality, and behavior. McGraw-Hill Education (UK), 2005.

Al-Maghrabi, T., Dennis, C., and Vaux Halliday, S. (2011). Antecedents of continuance intentions towards e-shopping: the case of Saudi Arabia. Journal of Enterprise Information Management, 24(1), 85-111.

Alahmad, M. A., Wheeler, P. G., Schwer, A., Eiden, J., and Brumbaugh, A. (2012). A comparative study of three feedback devices for residential real-time energy monitoring. Industrial Electronics, IEEE Transactions on, 59(4), 2002-2013.

Allen, T. F. (2004). Applying the principles of ecological emergence to building design and construction. CJ Kibert, Jan Sendzimir, and GB Guy (London: Spon, 2002), 108-26.

Azar, E., and Menassa, C. (2011). An agent-based approach to model the effect of occupants' energy use characteristics in commercial buildings. American Society of Civil Engineers (ASCE), 536-543. 
Azar, E., and Menassa, C. C. (2012). A comprehensive analysis of the impact of occupancy parameters in energy simulation of office buildings. Energy and Buildings, 55, 841-853.

Azar, E., and Menassa, C. C. (2014a). A comprehensive framework to quantify energy savings potential from improved operations of commercial building stocks. Energy Policy, 67, 459-472.

Azar, E. and Menassa, C. (2014b). "A Framework to Evaluate Energy Saving Potential from Occupancy Interventions in Typical US Commercial Buildings." Journal of Computing in Civil Engineering - Special Issue on Computational Approaches to Understand and Reduce Energy Consumption in the Built Environment, ASCE. 28 (1), 63-78.

Azar, E., and Menassa, C. C. (2015). Evaluating the impact of extreme energy use behavior on occupancy interventions in commercial buildings. Energy and Buildings, 97, 205-218.

Azevedo, I. M. (2014). Consumer end-use energy efficiency and rebound effects. Annual Review of Environment and Resources, 39, 393-418.

Bang, Magnus, Carin Torstensson, and Cecilia Katzeff. "The powerhhouse: A persuasive computer game designed to raise awareness of domestic energy consumption." International Conference on Persuasive Technology. Springer Berlin Heidelberg, 2006.

Bayus, B. and Mehta, R. (1995). "A Segmentation Model for the Targeted Marketing of Consumer Durables.” Journal of Marketing Research, 32 (4), 463-469.

Beheiry, S. M., Chong, W. K., \& Haas, C. T. (2006). Examining the business impact of owner commitment to sustainability. Journal of Construction Engineering and Management, 132(4), 384-392.

Bernstein, H. M., \& Russo, M. A. (2009). Green Building Retrofit and Renovation: Rapidly Expanding Market Opportunities through Existing Buildings, Smart Market Report.

Bigné, E., Hernández, B., Ruiz, C., and Andreu, L. (2010). How motivation, opportunity and ability can drive online airline ticket purchases. Journal of Air Transport Management, 16(6), 346-349.

Blumberg, Melvin, and Charles D. Pringle. "The missing opportunity in organizational research: Some implications for a theory of work performance." Academy of management Review 7.4 (1982): 560-569.

Bollen, K. A., and Long, J. S. (1993). Testing structural equation models, Sage. 
Bosch, S. J., and Pearce, A. R. (2003). Sustainability in public facilities: Analysis of guidance documents. Journal of Performance of Constructed Facilities, 17(1), 9-18.

Boyce, T. E., and Geller, E. S. (2001). Encouraging College Students to Support ProEnvironment Behavior Effects of Direct Versus Indirect Rewards. Environment and Behavior, 33(1), 107-125.

Bruner, G. C., and Kumar, A. (2005). Explaining consumer acceptance of handheld Internet devices. Journal of Business Research, 58(5), 553-558.

Buurma, H. (2001). Public policy marketing: marketing exchange in the public sector. European Journal of Marketing, 35(11/12), 1287-1302.

Carrico, A. R., and Riemer, M. (2011). Motivating energy conservation in the workplace: An evaluation of the use of group-level feedback and peer education. Journal of Environmental Psychology, 31(1), 1-13.

Celsi, R. L., and Olson, J. C. (1988). The role of involvement in attention and comprehension processes. Journal of consumer research, 210-224.

Chen, J., Taylor, J. E., \& Wei, H. H. (2012). Modeling building occupant network energy consumption decision-making: The interplay between network structure and conservation. Energy and Buildings, 47, 515-524.

Childers, T. L., Carr, C. L., Peck, J., and Carson, S. (2002). Hedonic and utilitarian motivations for online retail shopping behavior. Journal of retailing, 77(4), 511-535.

DEFRA (2008). A framework for pro-environmental behaviors? <https://www.gov.uk/government/uploads/system/uploads/attachment_data/file/69277/pb 13574-behaviours-report-080110.pdf>.

Dolan, P., and Metcalfe, R. (2013). Neighbors, knowledge, and nuggets: two natural field experiments on the role of incentives on energy conservation.

Eccles, M., Grimshaw, J., Walker, A., Johnston, M., and Pitts, N. (2005). Changing the behavior of healthcare professionals: the use of theory in promoting the uptake of research findings. Journal of clinical epidemiology, 58(2), 107-112.

Entrop, A., Brouwers, H., and Reinders, A. (2010). Evaluation of energy performance indicators and financial aspects of energy saving techniques in residential real estate. Energy and Buildings, 42(5), 618-629.

Fishbein, Martin, et al. "Factors influencing behavior and behavior change." (2001): 1-17. 
Fogg, Brian J. "A behavior model for persuasive design." Proceedings of the 4th international Conference on Persuasive Technology. ACM, 2009.

Geelen, D. V. "Stimulating energy efficiency in households: Comparison of the Livinggreen. eu methods to theory." Livinggreen Scientific Conference, Delft, The Netherlands, 19 April 2013. Delft University of Technology, 2013.

Geller, E. S. (1981). Evaluating energy conservation programs: Is verbal report enough? Journal of Consumer research, 331-335.

Govindaraju, R., Hadining, A. F., and Chandra, D. R. (2013). Physicians' Adoption of Electronic Medical Records: Model Development Using Ability-Motivation-Opportunity Framework. Information and Communication Technology, Springer, 41-49.

Greening, L. A., Greene, D. L., and Difiglio, C. (2000). Energy efficiency and consumption-the rebound effect - a survey. Energy policy, 28(6), 389-401.

Gruen, Thomas W., Talai Osmonbekov, and Andrew J. Czaplewski. "How e-communities extend the concept of exchange in marketing: An application of the motivation, opportunity, ability (MOA) theory." Marketing Theory 5.1 (2005): 33-49.

Hair, J. F. (2010). Multivariate data analysis.

Hallahan, K. (2001). Enhancing motivation, ability, and opportunity to process public relations messages. Public Relations Review, 26(4), 463-480.

Hastak, M., M.B. Mazis and L.A. Morris (2001) The role of consumer Surveys in Public Policy Decision Making. Journal of Public Policy \& Marketing, 20(2): 170-185.

Handgraaf, M. J., Van Lidth de Jeude, M. A., and Appelt, K. C. (2013). Public praise vs. private pay: Effects of rewards on energy conservation in the workplace. Ecological Economics, $86,86-92$.

Hayes, S. C., and Cone, J. D. (1977). REDUCING RESIDENTIAL ELECTRICAL ENERGY USE: PAYMENTS, INFORMATION, AND FEEDBACK1. Journal of Applied Behavior Analysis, 10(3), 425-435.

He, H. A., Greenberg, S., \& Huang, E. M. (2010). One size does not fit all: applying the transtheoretical model to energy feedback technology design. In Proceedings of the SIGCHI Conference on Human Factors in Computing Systems (pp. 927-936). ACM. 
Hines, Jody M., Harold R. Hungerford, and Audrey N. Tomera. "Analysis and synthesis of research on responsible environmental behavior: A meta-analysis." The Journal of environmental education 18.2 (1987): 1-8.

Hong, T. (2014). Occupant behavior: impact on energy use of private offices. In ASim 2012-1st Asia conference of International Building Performance Simulation Association., Shanghai, China, 11/25/12-11/27/12.

Hong, T., D'Oca, S., Turner, W. J., \& Taylor-Lange, S. C. (2015). An ontology to represent energy-related occupant behavior in buildings. Part I: Introduction to the DNAs framework. Building and Environment.

Hoyer, W.D. and MacInnis, D. (1997) Consumer Behavior. Boston, MA: Houghton Mifflin.

Jain, R. K., Gulbinas, R., Taylor, J. E., \& Culligan, P. J. (2013). Can social influence drive energy savings? Detecting the impact of social influence on the energy consumption behavior of networked users exposed to normative eco-feedback. Energy and Buildings, 66, 119-127.

Juan, Y.-K., Gao, P., and Wang, J. (2010). A hybrid decision support system for sustainable office building renovation and energy performance improvement. Energy and buildings, 42(3), 290-297.

Karatas, Aslihan, Allisandra Stoiko, and Carol C. Menassa. "Framework for selecting occupancy-focused energy interventions in buildings." Building Research \& Information 44.5-6 (2016): 535-551.

Klein, L., Kwak, J.-y., Kavulya, G., Jazizadeh, F., Becerik-Gerber, B., Varakantham, P., and Tambe, M. (2012). Coordinating occupant behavior for building energy and comfort management using multi-agent systems. Automation in Construction, 22, 525-536.

Kline, R. B., \& Santor, D. A. (1999). Principles \& Practice of Structural Equation Modelling. Canadian Psychology, 40(4), 381.

MacCallum, R. C., Browne, M. W., \& Sugawara, H. M. (1996). Power analysis and determination of sample size for covariance structure modeling. Psychological methods, 1(2), 130.

Machleit, K. A., Madden, T. J., and Allen, C. T. (1990). Measuring and modeling brand interest as an alternative ad effect with familiar brands. Advances in Consumer Research, 17(1). 
MacInnis, D. J., Moorman, C., and Jaworski, B. J. (1991). Enhancing and measuring consumers' motivation, opportunity, and ability to process brand information from ads. The Journal of Marketing, 32-53.

Mahdavi, A., and Pröglhöf, C. (2009). Toward empirically-based models of people's presence and actions in buildings. Proc., Proceedings of building simulation, 537-544.

Marans, R. W., and Edelstein, J. Y. (2010). The human dimension of energy conservation and sustainability: a case study of the University of Michigan's energy conservation program. International Journal of Sustainability in Higher Education, 11(1), 6-18.

Masoso, O. T., \& Grobler, L. J. (2010). The dark side of occupants' behaviour on building energy use. Energy and Buildings, 42(2), 173-177.

McMakin, A. H., Malone, E. L., and Lundgren, R. E. (2002). Motivating residents to conserve energy without financial incentives. Environment and Behavior, 34(6), 848-863.

MacQueen, J. B. (1967): "Some Methods for classification and Analysis of Multivariate Observations." Proceedings of 5-th Berkeley Symposium on Mathematical Statistics and Probability", Berkeley, University of California Press, 1:281-297

Michie, Susan, Maartje M. van Stralen, and Robert West. "The behaviour change wheel: a new method for characterising and designing behaviour change interventions." Implementation Science 6.1 (2011): 1.

Minitab (2014). How to Interpret a Regression Model with Low R-squared and Low P values? $<$ http://blog.minitab.com/blog/adventures-in-statistics/how-to-interpret-a-regressionmodel-with-low-r-squared-and-low-p-values>.

Moezzi, M., Iyer, M., Lutzenhiser, L., and Woods, J. (2009). Behavioral assumptions in energy efficiency potential studies. May. Prepared for the California Institute for Energy and Environment (CIEE). Oakland, Calif.

Moorman, C. (1990). The effects of stimulus and consumer characteristics on the utilization of nutrition information. Journal of Consumer Research, 362-374.

Moorman, C., \& Matulich, E. (1993). A model of consumers' preventive health behaviors: The role of health motivation and health ability. Journal of Consumer Research, 208-228.

Nemry, F., Uihlein, A., Colodel, C. M., Wetzel, C., Braune, A., Wittstock, B., Hasan, I., Kreißig, J., Gallon, N., and Niemeier, S. (2010). Options to reduce the environmental impacts of 
residential buildings in the European Union-Potential and costs. Energy and Buildings, 42(7), 976-984.

Nunnally, J. (1978). Psychometric methods. New York: McGraw-Hill.

Parra-Lopez, E., Gutierrez-Tano, D., Diaz-Armas, R. J., and Bulchand-Gidumal, J. (2012). Travellers 2.0: motivation, opportunity and ability to use social media. Social Media in Travel, Tourism and Hospitality, 171-185.

Peschiera, G., and Taylor, J. E. (2012). The impact of peer network position on electricity consumption in building occupant networks utilizing energy feedback systems. Energy and Buildings, 49, 584-590.

Peschiera, G., Taylor, J. E., and Siegel, J. A. (2010). Response-relapse patterns of building occupant electricity consumption following exposure to personal, contextualized and occupant peer network utilization data. Energy and Buildings, 42(8), 1329-1336.

Petkov, Petromil, et al. "Personalised eco-feedback as a design technique for motivating energy saving behaviour at home." Proceedings of the 7th Nordic Conference on HumanComputer Interaction: Making Sense Through Design. ACM, 2012.

Pieters, Rik, et al. "Consumers' attributions of proenvironmental behavior, motivation, and ability to self and others." Journal of Public Policy \& Marketing (1998): 215-225.

Poel, B., van Cruchten, G., and Balaras, C. A. (2007). Energy performance assessment of existing dwellings. Energy and Buildings, 39(4), 393-403.

Polonsky, M. J., Binney, W., and Hall, J. (2004). Developing Better Public Policy to Motivate Responsible Environmental Behavior-An Examination of Managers' Attitudes and Perceptions Towards Controlling Introduced Species. Journal of nonprofit \& public sector marketing, 12(1), 93-107.

Poortinga, Wouter, Linda Steg, and Charles Vlek. "Values, environmental concern, and environmental behavior a study into household energy use." Environment and behavior 36.1 (2004): 70-93.

Ray, G., Muhanna, W. A., and Barney, J. B. (2005). Information technology and the performance of the customer service process: A resource-based analysis. Mis Quarterly, 625-652.

Richins, M. L., and Bloch, P. H. (1986). After the new wears off: the temporal context of product involvement. Journal of Consumer research, 280-285. 
Rosenzweig, E. D., Roth, A. V., and Dean Jr, J. W. (2003). The influence of an integration strategy on competitive capabilities and business performance: an exploratory study of consumer products manufacturers. Journal of Operations Management, 21(4), 437-456.

Rothschild, M. L. (1999). Carrots, sticks, and promises: a conceptual framework for the management of public health and social issue behaviors. The Journal of Marketing, 2437.

Ruzelli, A. (2010). Proceedings of the 2nd ACM Workshop on Embedded Sensing Systems for Energy-Efficiency in Building. ACM, 1878431, 93.

Sanchez, M., Webber, C., Brown, R., Busch, J., Pinckard, M., and Roberson, J. (2007). Space heaters, computers, cell phone chargers: How plugged in are commercial buildings? Lawrence Berkeley National Laboratory.

Schweiker, M., \& Shukuya, M. (2010). Comparative effects of building envelope improvements and occupant behavioural changes on the exergy consumption for heating and cooling. Energy Policy, 38(6), 2976-2986.

Scofield, J. H. (2009). Do LEED-certified buildings save energy? Not really.... Energy and Buildings, 41(12), 1386-1390.

Shove, Elizabeth. "Beyond the ABC: climate change policy and theories of social change." Environment and planning A 42.6 (2010): 1273-1285.

Southwell, B. G., and Torres, A. (2006). Connecting interpersonal and mass communication: Science news exposure, perceived ability to understand science, and conversation. Communication Monographs, 73(3), 334-350.

Sovacool, Benjamin K. "What are we doing here? Analyzing fifteen years of energy scholarship and proposing a social science research agenda." Energy Research \& Social Science 1 (2014): 1-29.

Staddon, Sam C., et al. "Intervening to change behaviour and save energy in the workplace: A systematic review of available evidence." Energy Research \& Social Science 17 (2016): $30-51$.

Stata (2013). Stata Structural Equation Modeling Reference Manual (Release 13). < http://www.stata.com/manuals13/sem.pdf >.

Steg, L., and Vlek, C. (2009). Encouraging pro-environmental behaviour: An integrative review and research agenda. Journal of environmental psychology, 29(3), 309-317. 
Stephenson, Janet, et al. "Energy cultures: A framework for understanding energy behaviours." Energy policy 38.10 (2010): 6120-6129.

Sudbury, L. and Simock, P. (2009). "A multivariate segmentation model of senior consumers." Journal of Consumer Marketing, 26 (4), 251-262.

Tanimoto, J., and Hagishima, A. (2009). Total Utility Demand Prediction Based on Probabilistically Generated Behaviroal Schedules ff Actural Inhabitants.

ThØgersen, John. "Understanding of consumer behaviour as a prerequisite for environmental protection." Journal of consumer policy 18.4 (1995): 345-385.

Timm, Stephanie N., and Brian M. Deal. "Effective or ephemeral? The role of energy information dashboards in changing occupant energy behaviors." Energy Research \& Social Science 19 (2016): 11-20.

UNEP (2010). Common Carbon Metric for Measuring Energy Use \& Reporting Greenhouse Gas Emissions from Building Operations. <http://www.unep.org/sbci/pdfs/UNEPSBCICarbonMetric.pdf>. (12/31, 2010).

US EIA (2014). How much energy is consumed in residential and commercial buildings in the United States? <http://www.eia.gov/tools/faqs/faq.cfm?id=86\&t=1>. (12/31, 2014).

US Energy Information Administration, Commercial Buildings Energy Consumption Survey (2003).

Van der Heijden, H., Verhagen, T., and Creemers, M. (2003). Understanding online purchase intentions: contributions from technology and trust perspectives. European journal of information systems, 12(1), 41-48.

Van Houwelingen, J. H., and Van Raaij, W. F. (1989). The effect of goal-setting and daily electronic feedback on in-home energy use. Journal of consumer research, 98-105.

Vlek, Charles. "Essential psychology for environmental policy making." International Journal of Psychology 35.2 (2000): 153-167.

Von Borgstede, C., Andersson, M., \& Johnsson, F. (2013). Public attitudes to climate change and carbon mitigation-Implications for energy-associated behaviours. Energy Policy, 57, 182-193.

Wang, J.-J., Jing, Y.-Y., Zhang, C.-F., and Zhao, J.-H. (2009). Review on multi-criteria decision analysis aid in sustainable energy decision-making. Renewable and Sustainable Energy Reviews, 13(9), 2263-2278. 
Maslow, Abraham. "Maslow's hierarchy of needs." Salenger Incorporated (1987).

Webber, C. A., Roberson, J. A., McWhinney, M. C., Brown, R. E., Pinckard, M. J., and Busch, J. F. (2006). After-hours power status of office equipment in the USA. Energy, 31(14), 2823-2838.

Whitsett, D. D., Justus, H. C., Steiner, E., and Duffy, K. (2013). Persistence of Energy Efficiency Behaviors over Time: Evidence from a Community-Based Program.

Wilson, C., and Dowlatabadi, H. (2007). Models of decision making and residential energy use. Annu. Rev. Environ. Resour., 32, 169-203.

Wilson, Caroline, and Melissa R. Marselle. "Insights from psychology about the design and implementation of energy interventions using the Behaviour Change Wheel." Energy Research \& Social Science 19 (2016): 177-191.

Wolff, L., Massett, H., Maibachc, E., Weberd, D., Hassmillere, S. and Mockenhaupte, R. (2010). "Validating a Health Consumer Segmentation Model: Behavioral and Attitudinal Differences in Disease Prevention-Related Practices.” Journal of Health Communication: International Perspectives, 15 (2), 167-188.

Wong, N. H., Cheong, D., Yan, H., Soh, J., Ong, C., and Sia, A. (2003). The effects of rooftop garden on energy consumption of a commercial building in Singapore. Energy and buildings, 35(4), 353-364.

Yudelson, J. (2010). Greening existing buildings, McGraw-Hill New York.

Zaichkowsky, J. L. (1985). Measuring the involvement construct. Journal of consumer research, 341-352. 
Table 1: Application of the MOA Model to the Study of Energy Use Characteristics

\begin{tabular}{|c|c|c|}
\hline $\begin{array}{l}\text { Psychological definition } \\
\text { ( Blumberg and Pringle } \\
\text { 1982; Gruen et al. 2005; } \\
\text { Hoyer and MacInnis 1997; } \\
\text { Michie et al. 2011) }\end{array}$ & $\begin{array}{l}\text { MOA model in consumer science } \\
\text { (Celsi and Olson 1988; MacInnis et al. } \\
\text { 1991; Moorman and Matulich 1993; } \\
\text { Rothschild 1999, etc.) }\end{array}$ & $\begin{array}{l}\text { Proposed framework with adapted MOA } \\
\text { model in energy efficiency }\end{array}$ \\
\hline $\begin{array}{l}\text { Motivation is defined as the } \\
\text { brain processes that } \\
\text { energize and direct human } \\
\text { behavior toward goals }\end{array}$ & $\begin{array}{l}\text { Motivation is defined as consumers' } \\
\text { interest, desire and readiness to engage } \\
\text { themselves in processing the brand } \\
\text { information in an ad and their willingness to } \\
\text { perform purchasing behavior. E.g., high } \\
\text { motivation consumer is willing to pay } \\
\text { his/her attention to the advertised message }\end{array}$ & $\begin{array}{l}\text { Motivation measures an occupant's needs, } \\
\text { goals and values (self-related knowledge), and } \\
\text { the level of involvement with energy use } \\
\text { information, whether occupants' are concern } \\
\text { about their personal energy consumption and } \\
\text { looking for ways to save energy from various } \\
\text { sources }\end{array}$ \\
\hline $\begin{array}{l}\text { Opportunity is defined as } \\
\text { external factors (lie outside } \\
\text { the individual) that make } \\
\text { the behavior possible or } \\
\text { prompt it }\end{array}$ & $\begin{array}{l}\text { Opportunity is defined as the environment } \\
\text { factors (e.g., distraction, lack of conditions, } \\
\text { limited exposure time) which affect } \\
\text { consumer's attention to brand information } \\
\text { in an ad. E.g., Consumers who are } \\
\text { unfamiliar with a brand may choose other } \\
\text { competitive products }\end{array}$ & $\begin{array}{l}\text { Opportunity measures an occupant's } \\
\text { availability and accessibility to the energy } \\
\text { saving information and energy control system, } \\
\text { as well as some environmental and } \\
\text { interpersonal factors that may affect occupants } \\
\text { processing these information in his/her } \\
\text { environment (both physical and social } \\
\text { opportunity) }\end{array}$ \\
\hline $\begin{array}{l}\text { Ability is defined as } \\
\text { necessary psychological } \\
\text { and physical capabilities to } \\
\text { make an outcome happen }\end{array}$ & $\begin{array}{l}\text { Ability is defined as consumers' resources, } \\
\text { skills, or proficiencies in interpreting brand } \\
\text { information and performing the purchasing } \\
\text { behavior. E.g., high ability consumer is able } \\
\text { to search desired items online and compared } \\
\text { with different brands }\end{array}$ & $\begin{array}{l}\text { Ability is a knowledge-based measure which } \\
\text { affects how an occupant interpret and process } \\
\text { the energy saving information. Ability } \\
\text { implicates an occupant's prior knowledge about } \\
\text { energy use, its impact and consequences, as } \\
\text { well as knowledge about possible saving } \\
\text { strategies }\end{array}$ \\
\hline
\end{tabular}




\section{Table 2: Metrics for Measuring Occupants' MOA for Energy Conservation}

\begin{tabular}{|c|c|}
\hline Metrics of Construct & Measures \\
\hline $\begin{array}{l}\text { Measures of Motivation (M) } \\
\text { Self-related Knowledge (Internal Stimuli) } \\
\text { • Needs } \\
\text { • Goals } \\
\text { • Values } \\
\text { Energy Use Knowledge (External Stimuli) } \\
\quad \text { - Level of Energy Use } \\
\text { - Impact and Consequences }\end{array}$ & $\begin{array}{l}\text { Assess self-awareness about importance of Energy Use Knowledge } \\
\text { Measure desire to receive Energy Use Knowledge } \\
\text { Detect norms of avoiding Energy Use Knowledge (e.g., not interested in } \\
\text { attending workshops or receiving emails) }\end{array}$ \\
\hline $\begin{array}{l}\text { Measures of Opportunity }(\mathbf{O}) \\
\text { Ease of implementation } \\
\text { Amount of Information } \\
\text { Information Format } \\
\text { Modality } \\
\text { Rate of Exposure to Information } \\
\end{array}$ & $\begin{array}{l}\text { Determine number of times: } \\
\text { Accessible and easy to use controls (e.g., thermostat, lighting, shading) } \\
\text { Attend awareness seminars } \\
\text { Read information on general advertisement boards (self-reported) } \\
\text { Read emails (ask for response with a blank email) } \\
\text { Discuss with peers (self-reported) }\end{array}$ \\
\hline $\begin{array}{l}\text { Measures of Ability (A) } \\
\text { Energy Use Prior Knowledge } \\
\text { - Impact } \\
\text { - Consequences } \\
\text { - Conservation Strategies }\end{array}$ & $\begin{array}{l}\text { Measure extent conservation strategies are used (e.g., estimate number of } \\
\text { times consciously turn lights off at end of the day) } \\
\text { Measure subjective knowledge of energy use relative to average person } \\
\text { Measure actual knowledge (i.e., factual information): } \\
\text { - Terminology } \\
\text { - } \quad \text { Possible impacts/consequences } \\
\text { - Criteria to evaluate impacts/consequences } \\
\text { - Perceived effectiveness of intervention strategy to reduce } \\
\text { impacts/consequences }\end{array}$ \\
\hline
\end{tabular}


Table 3: Measures for Occupants' MOA through Reliability Analysis

\begin{tabular}{|c|c|c|c|}
\hline \multicolumn{4}{|c|}{ Measures that can be combined into single construct } \\
\hline Construct & Highly Correlated Measures & Cronbach $\alpha$ & Single Construct \\
\hline $\begin{array}{c}\text { Opportunity } \\
\text { (Control systems) }\end{array}$ & $\begin{array}{l}\text { Availability of the office equipment as follows: } \\
\text { (1) printer } \\
\text { (2) fax } \\
\text { (3) fridge } \\
\text { (4) microwave oven }\end{array}$ & 0.812 & Plug load \\
\hline $\begin{array}{l}\text { Opportunity } \\
\text { (Expose to information) }\end{array}$ & $\begin{array}{l}\text { My company performs the actions as follows: } \\
\text { (1) taking energy conservation very seriously } \\
\text { (2) encouraging all staff to conserve energy } \\
\text { (3) providing all staff with strategies to conserve energy }\end{array}$ & 0.868 & Company's actions \\
\hline $\begin{array}{l}\text { Opportunity } \\
\text { (Expose to peer } \\
\text { pressure) }\end{array}$ & $\begin{array}{l}\text { I would feel comfortable explaining to (1) my close } \\
\text { friends; (2) other colleagues in the company how they can } \\
\text { conserve energy. } \\
\text { My (3) close friends; (4) other colleagues in the company } \\
\text { always use strategies to conserve energy. }\end{array}$ & 0.839 & Peer pressure \\
\hline Motivation & $\begin{array}{l}\text { (1) How concerned are you about your personal energy } \\
\text { consumption at your office? } \\
\text { (2) How often do you look for ways to conserve energy at } \\
\text { your office? } \\
\text { (3) How important are the following factors to you in } \\
\text { deciding whether to conserve energy? (e.g., it is morally } \\
\text { the right thing to do) }\end{array}$ & 0.760 & Motivation \\
\hline $\begin{array}{l}\text { Ability } \\
\text { (Perceived energy } \\
\text { conservation } \\
\text { knowledge) }\end{array}$ & $\begin{array}{l}\text { I know methods to reduce the power load as follows: } \\
\text { (1) lighting } \\
\text { (2) cooling } \\
\text { (3) heating } \\
\text { (4) plug load }\end{array}$ & 0.861 & $\begin{array}{l}\text { Perceived energy } \\
\text { conservation } \\
\text { knowledge }\end{array}$ \\
\hline \multicolumn{4}{|c|}{ Measures that exist individually } \\
\hline MOA Category & Measure Description & \multicolumn{2}{|c|}{ Single Construct } \\
\hline Opportunity & Availability of the lighting control & \multicolumn{2}{|c|}{ Lighting control } \\
\hline (Control systems) & Availability of the thermostat control & \multicolumn{2}{|c|}{ Thermostat control } \\
\hline & $\begin{array}{l}\text { How do you describe the quality of artificial light in your } \\
\text { work area? }\end{array}$ & \multicolumn{2}{|c|}{ Lighting quality } \\
\hline $\begin{array}{l}\text { Opportunity } \\
\text { (Environment }\end{array}$ & $\begin{array}{l}\text { How do you describe the quality of thermal comfort in } \\
\text { your work area? }\end{array}$ & \multicolumn{2}{|c|}{ Thermal comfort } \\
\hline & $\begin{array}{l}\text { How do you describe the indoor air quality in your work } \\
\text { area? }\end{array}$ & \multicolumn{2}{|c|}{ Indoor air quality } \\
\hline $\begin{array}{c}\text { Ability } \\
\text { (Knowledge on energy } \\
\text { consumption facts) } \\
\end{array}$ & $\begin{array}{l}\text { Questions aiming to test occupants' knowledge about } \\
\text { energy consumption facts (e.g., Which of the following } \\
\text { energy resources is not renewable?) }\end{array}$ & \multicolumn{2}{|c|}{$\begin{array}{c}\text { Knowledge on energy consumption } \\
\text { facts }\end{array}$} \\
\hline \multicolumn{4}{|c|}{ Measures that are removed due to non-applicability } \\
\hline MOA Category & $\begin{array}{l}\text { Measure Description } \\
\end{array}$ & \multicolumn{2}{|c|}{ Removed Construct } \\
\hline \multirow{3}{*}{$\begin{array}{c}\text { Opportunity } \\
\text { (Control systems) }\end{array}$} & Availability of the task lighting & \multicolumn{2}{|c|}{ Control of task lighting } \\
\hline & Availability of the space heater & \multicolumn{2}{|c|}{ Control of space heater } \\
\hline & Availability of the coffee machine & \multicolumn{2}{|c|}{ Control of coffee machine } \\
\hline \multirow{2}{*}{$\begin{array}{l}\text { Opportunity } \\
\text { (Environment } \\
\text { satisfaction) }\end{array}$} & $\begin{array}{l}\text { How do you describe the quality of natural lighting in } \\
\text { your work area? }\end{array}$ & \multicolumn{2}{|c|}{ Quality level of natural lighting } \\
\hline & How do you describe the glare comfort in your work area? & \multicolumn{2}{|c|}{ Quality of glare comfort } \\
\hline
\end{tabular}


Table 4: Results from Structural Equation Modeling (SEM) Analysis

\begin{tabular}{|c|c|c|}
\hline \multicolumn{2}{|l|}{ Outcome } & \multirow{2}{*}{ Coeff. $(\beta)$} \\
\hline Behavior & & \\
\hline \multirow{23}{*}{ Motivation } & Motivation $\rightarrow$ Behavior $($ H1) & \\
\hline & Motivation Level $\rightarrow$ Turning off the office room lights when not in use & $0.34 * *$ \\
\hline & Motivation Level $\rightarrow$ Turning off the office monitor when not in use & $0.24 * *$ \\
\hline & Motivation Level $\rightarrow$ Energy conservation behavior when the office is too chilly/cold & -0.02 \\
\hline & Motivation Level $\rightarrow$ Energy conservation behavior when the office is too warm/hot & -0.03 \\
\hline & & \\
\hline & Opportunity $\rightarrow$ Motivation & \\
\hline & $\mathrm{H} 2 \rightarrow \mathrm{H} 1$ & \\
\hline & Control on Lighting $\rightarrow$ Motivation Level & -0.11 \\
\hline & Control on Thermostat Settings $\rightarrow$ Motivation Level & $-0.32 *$ \\
\hline & Control on Office Equipment Plug Load $\rightarrow$ Motivation Level & 0.13 \\
\hline & $\mathrm{H} 3 \rightarrow \mathrm{H} 1$ & \\
\hline & Indoor Lighting Comfort Level $\rightarrow$ Motivation Level & -0.06 \\
\hline & Thermal Comfort Level $\rightarrow$ Motivation Level & $0.16 *$ \\
\hline & Indoor Air Quality Level $\rightarrow$ Motivation Level & -0.09 \\
\hline & $\mathrm{H} 4 \rightarrow \mathrm{H} 1$ & \\
\hline & Exposed to Information $\rightarrow$ Motivation Level & -0.01 \\
\hline & Peer Pressure $\rightarrow$ Motivation Level & $0.19 *$ \\
\hline & Ability $\rightarrow$ Motivation & \\
\hline & $\mathrm{H} 5 \rightarrow \mathrm{H} 1$ & \\
\hline & Perceived Self-Knowledge on Energy Conservation $\rightarrow$ Motivation Level & $0.23 * *$ \\
\hline & $\mathrm{H} 6 \rightarrow \mathrm{H} 1$ & \\
\hline & Knowledge on Energy Use Facts $\rightarrow$ Motivation Level & 0.16 \\
\hline
\end{tabular}

* Statistically significant $(\mathrm{p}<0.1)$

$* *$ Statistically significant $(\mathrm{p}<0.05)$ 
Table 5: Centroid of Each Category for the Case Study Building

\begin{tabular}{|c|c|c|c|c|}
\hline Number of Occupants & $\begin{array}{c}\text { Occupancy } \\
\text { Characteristics }\end{array}$ & M & O & A \\
\hline 29 & Prone & 80 & 51 & 61 \\
\hline 30 & Mildly Unable & 56 & 43 & 32 \\
\hline 29 & Unable & 53 & 40 & 66 \\
\hline 37 & Mildly Resistant & 52 & 61 & 53 \\
\hline 5 & Resistant & 20 & 30 & 21 \\
\hline
\end{tabular}




\begin{tabular}{|c|l|}
\multicolumn{1}{c|}{ Persuasion } & \multirow{2}{*}{ Tenalties } \\
\hline Emphasis on occupant orientation and behavior maintenance & Emphasis on making the individual behavior obsolete \\
\hline Voluntary Behavior Change & Involuntary Behavior Change due to change in context \\
\hline$\longrightarrow$ & Increased Economic and Environmental Costs \\
\hline
\end{tabular}

Figure 1: Multi-Level Building Energy Use Intervention Strategies 


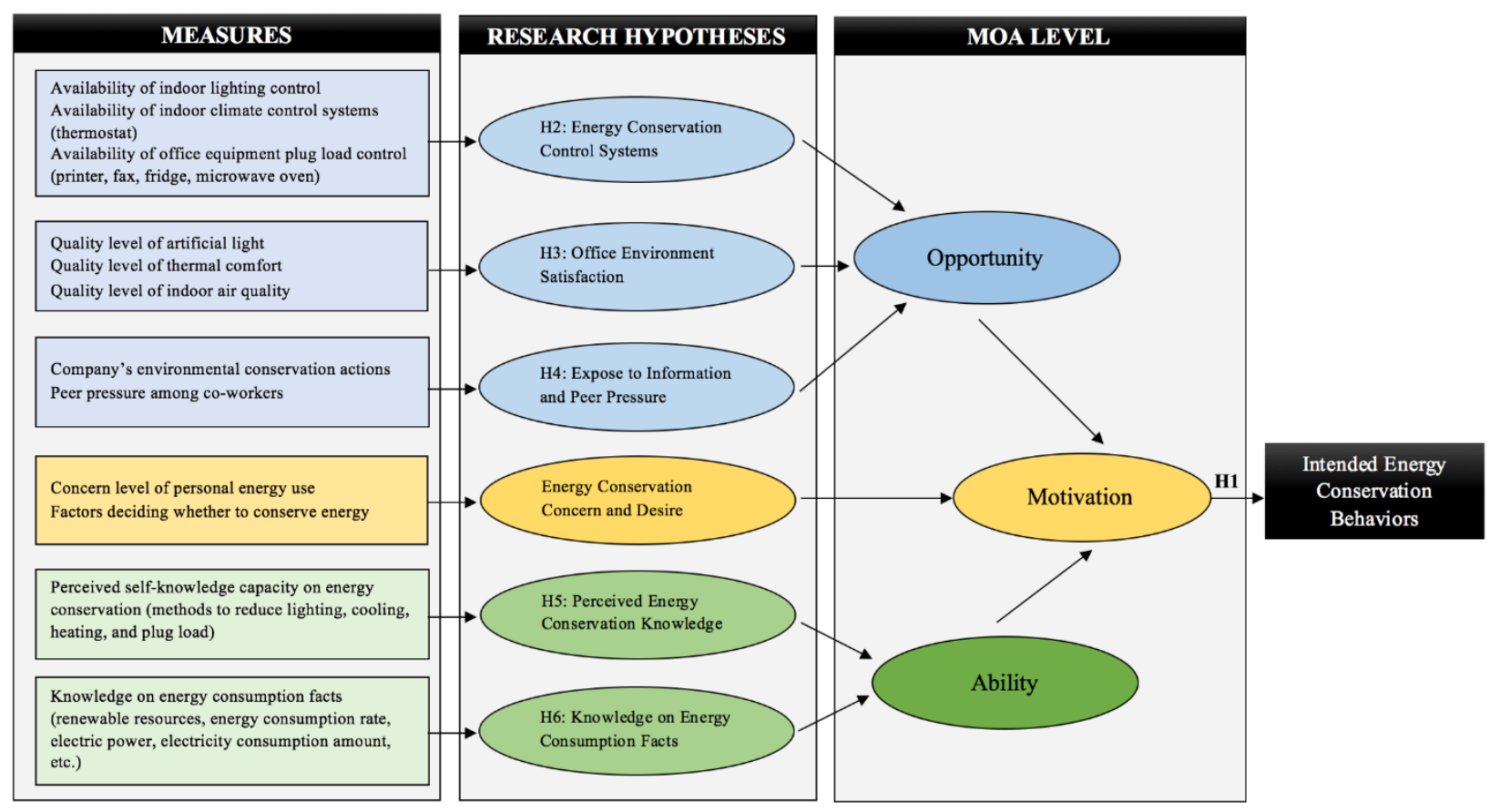

Figure 2: Measures for MOA Level of Occupants' Energy-Use Behavior 


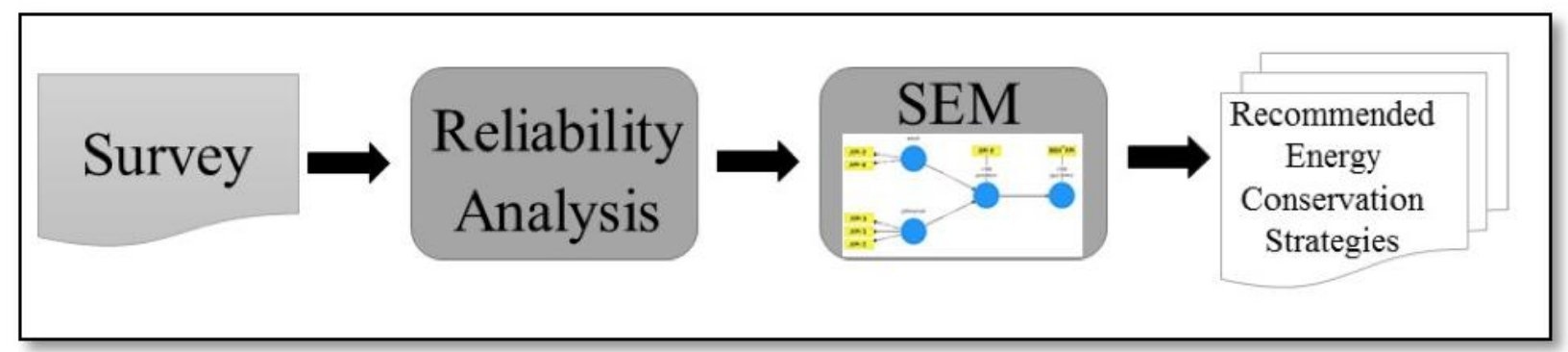

Figure 3: Framework Implementation 

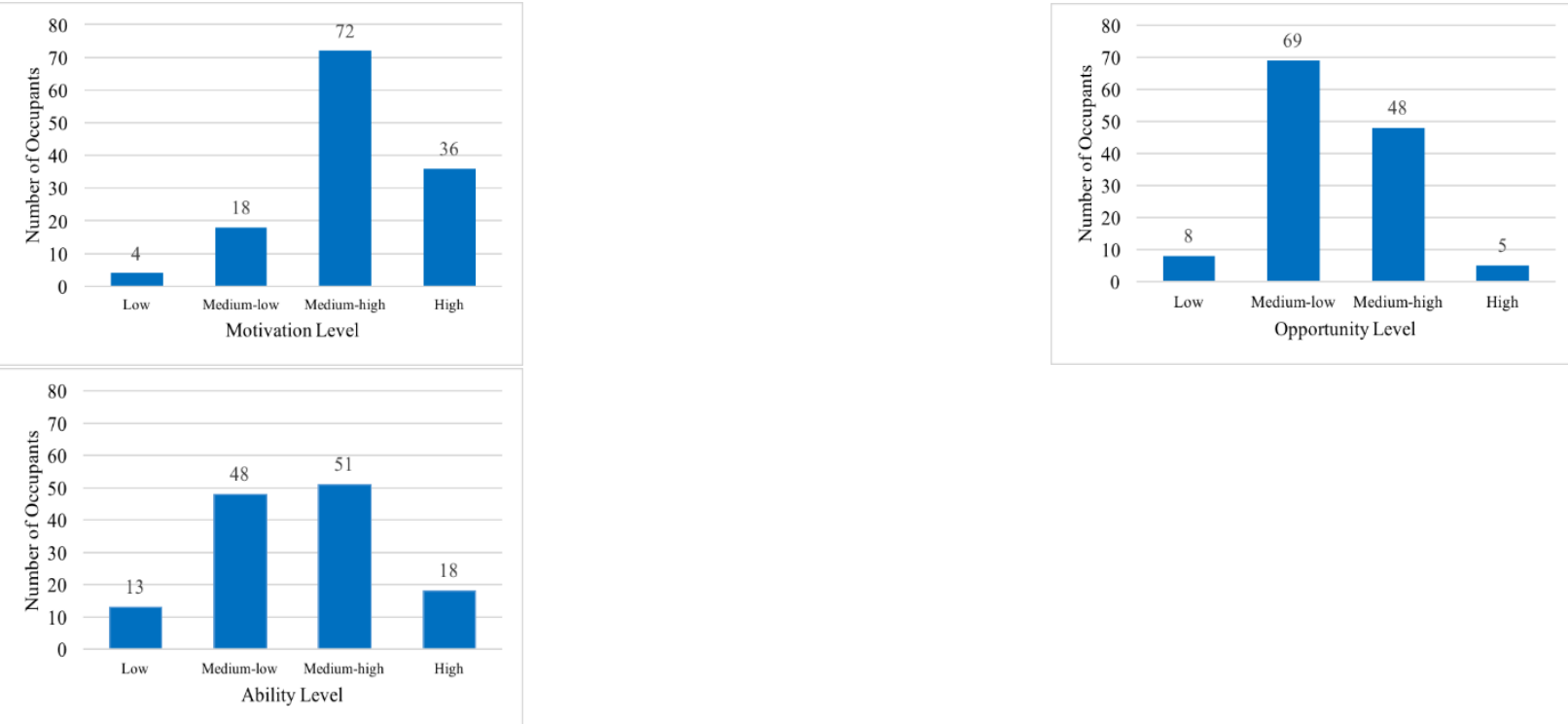

(a)

(b)

(c)

Figure 4: Occupants' (a) Motivation Level; (b) Opportunity Level; (c) Ability Level 


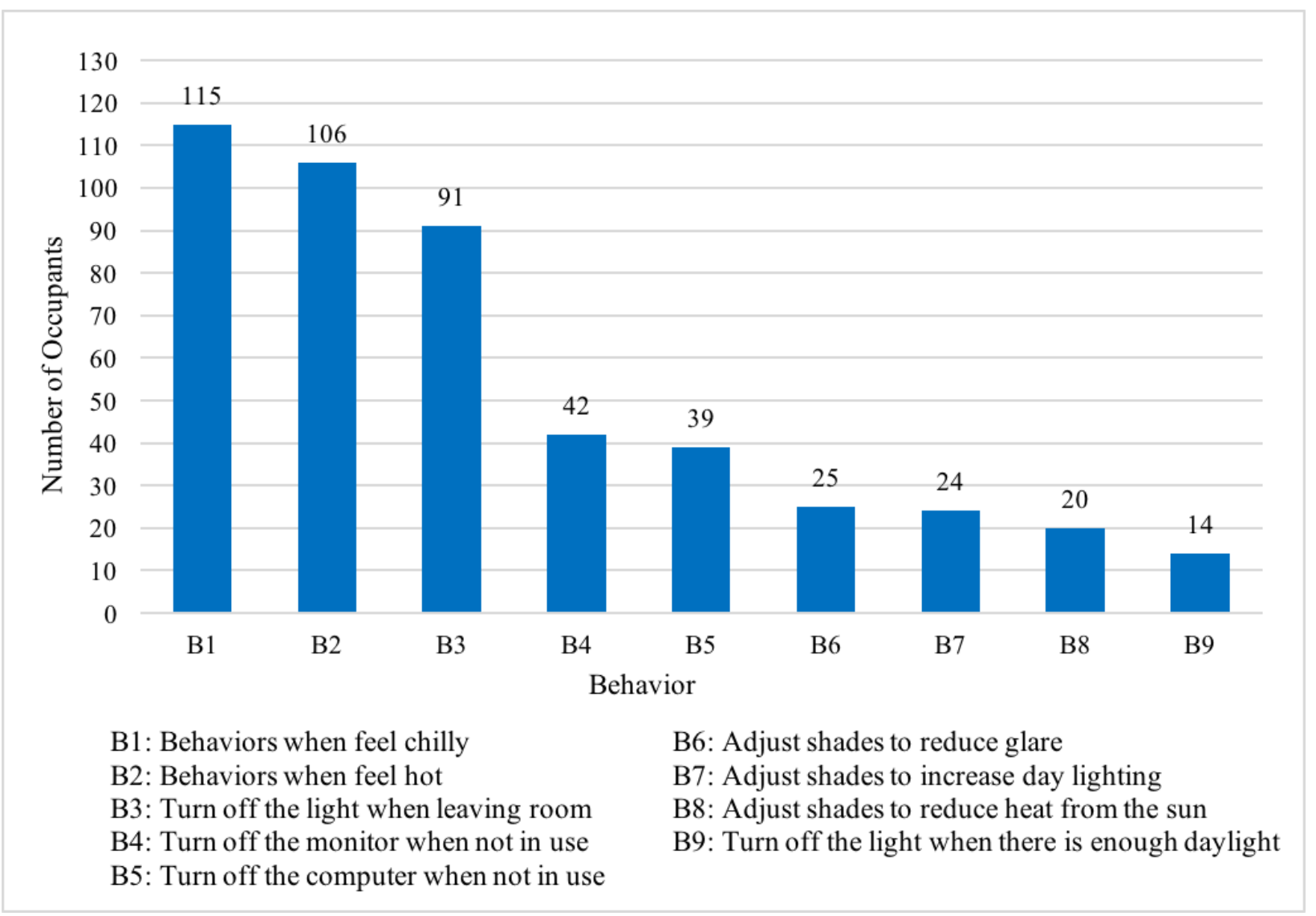

Figure 5: Number of Occupants Who Perform Better Energy Use Behaviors 


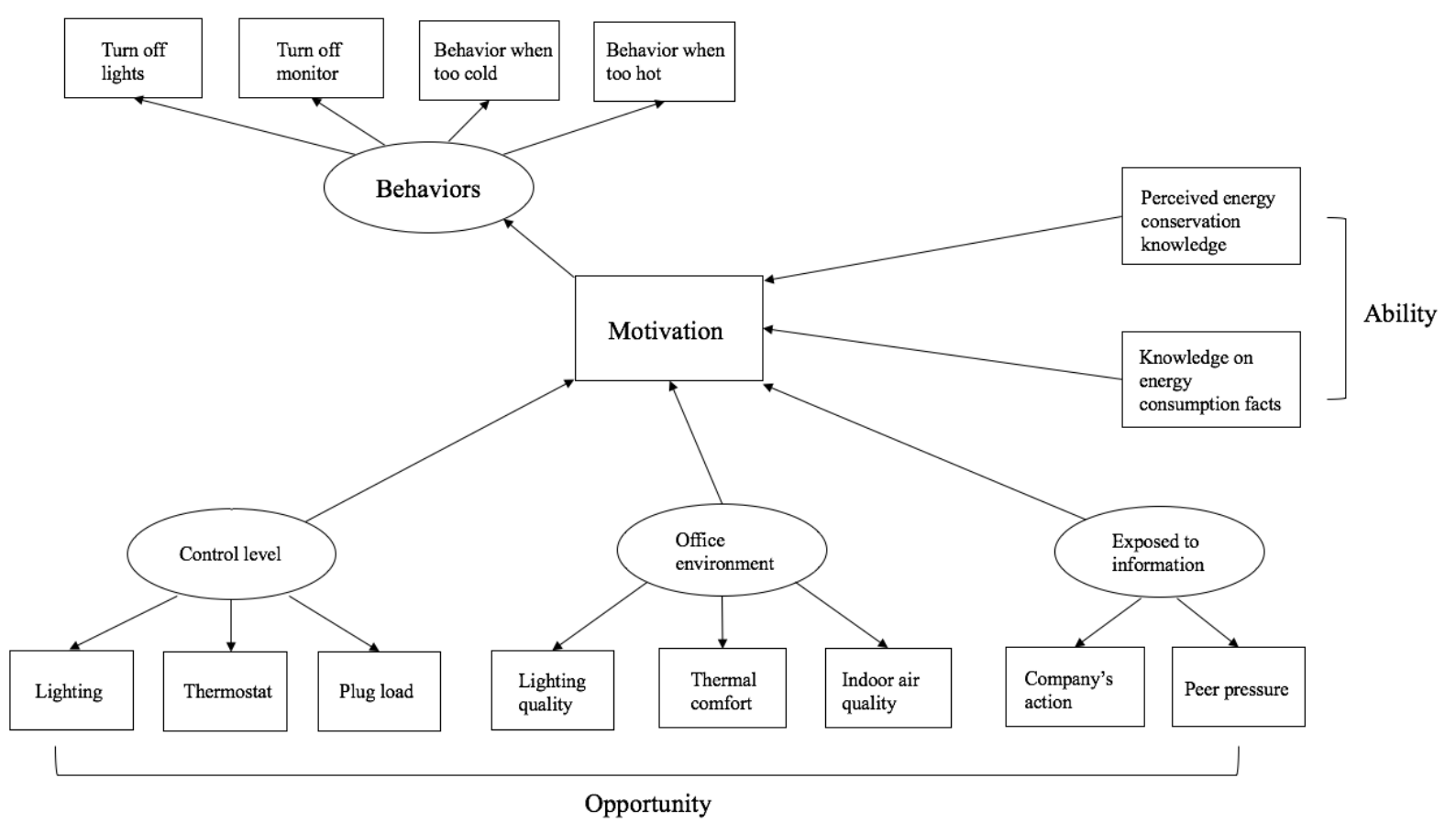

Figure 6: SEM Model for the Case Study Building 


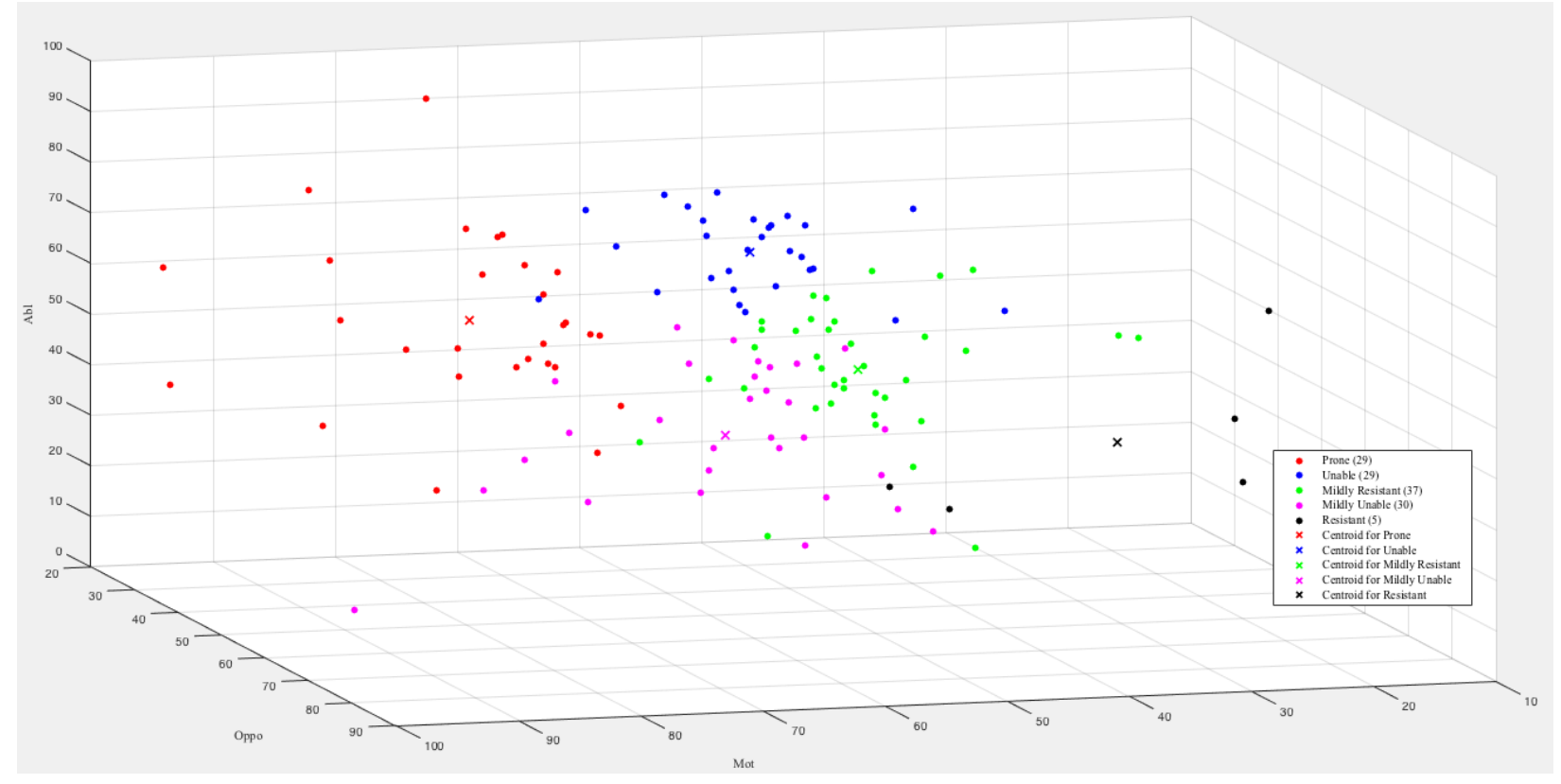

Figure 7: K-means Clustering Analysis for Occupants in the Case Study Building 
$\longrightarrow$ Original Number of Occupants $\longrightarrow$ Number of Occupants who Reduced Energy Consumption

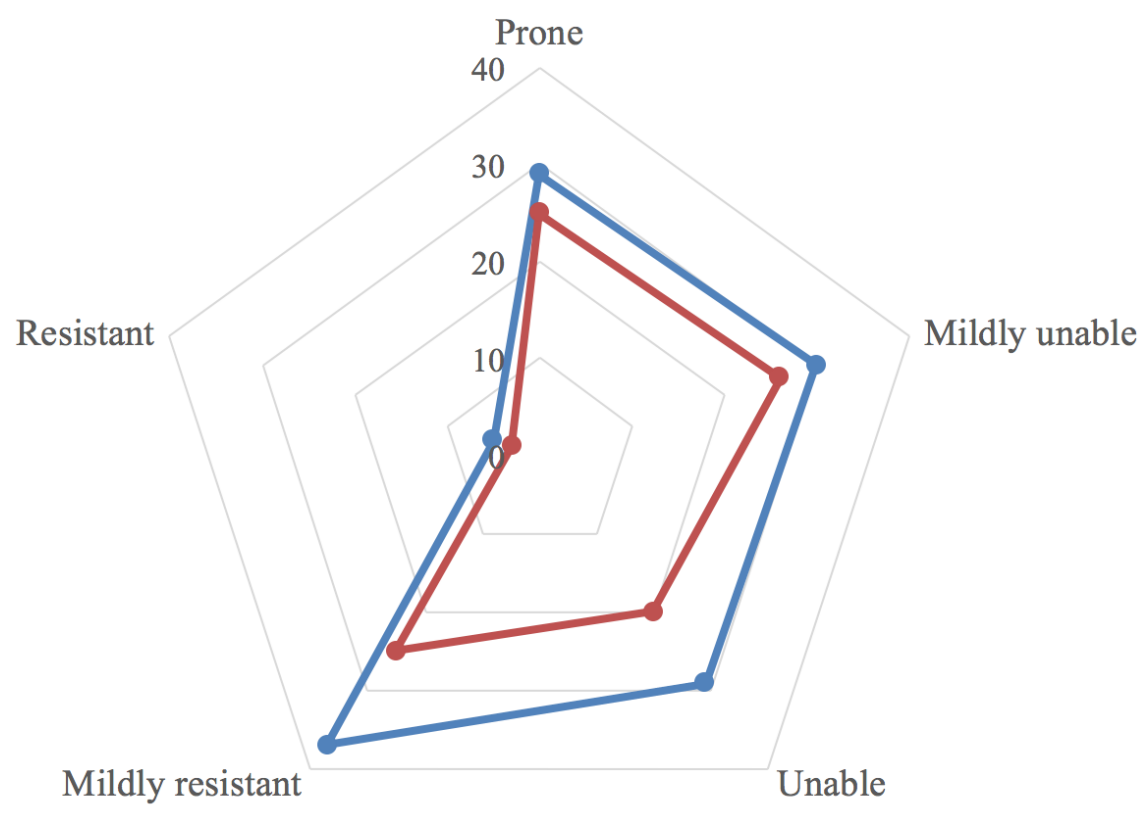

Figure 8: Distribution of Occupants Who Reduced Energy Consumption in Each Category 


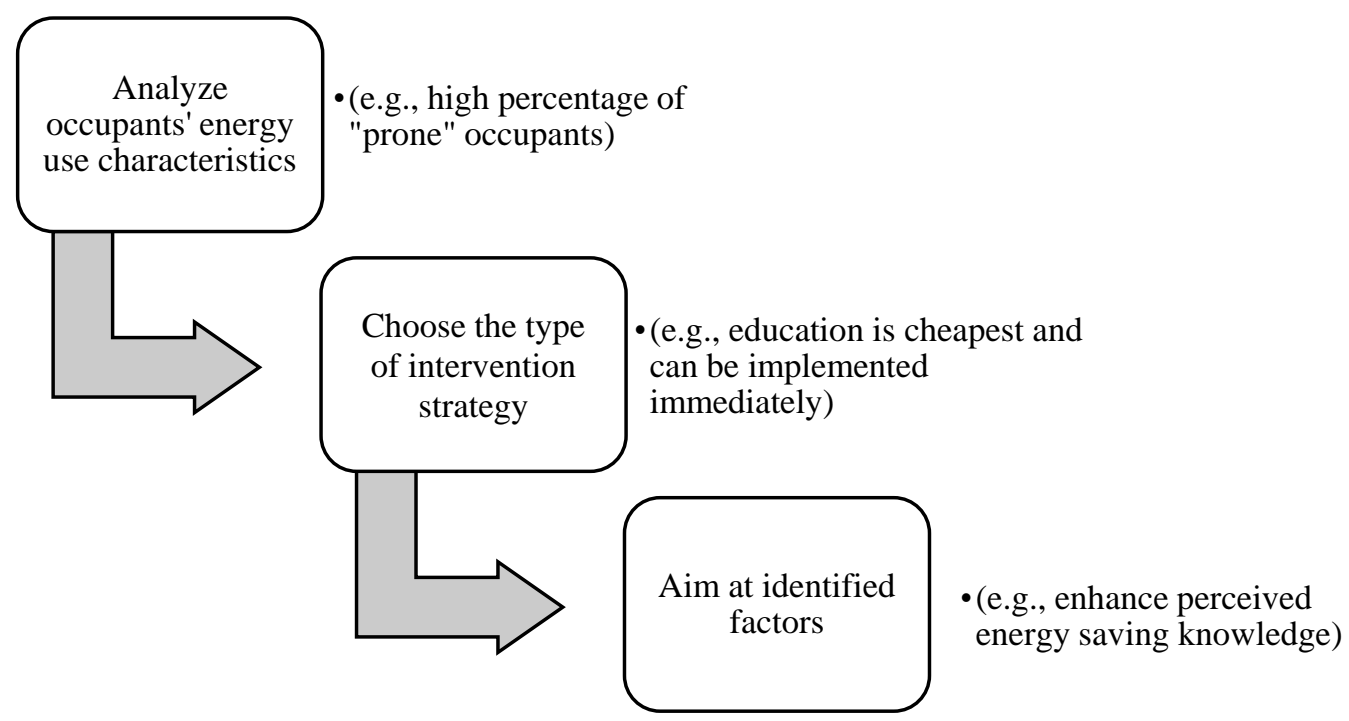

Figure 9: Steps for Designing Occupancy-Focused Intervention Strategies 